\title{
THE EFFECT OF INNOVATION ON SMALL AND MEDIUM ENTERPRISES: A BIBLIOMETRIC ANALYSIS
}

\author{
Reham Al-Hanakta*, Bálint Csaba Illés, Anna Dunay, \\ Gemechu Shuremo Abdissa, Mehrzad Abdi Khalife
}

Hungarian University of Agriculture and Life Sciences, Gödöllő, Hungary

\begin{abstract}
Innovation plays great role in organizational competitiveness and sustainable business processes and it should be a key success policy for small and medium-sized enterprises (SMEs) all over the world. To this effect, the purpose of this study is to present a comprehensive understanding of the scientific studies made on the field of innovation and its effect on small and medium enterprises performance. A bibliometric study was used to analyze articles published between 1976 and 2020 and create an illustrative map of innovation in small and medium enterprises; a sample of papers gathered through Web of Science Core Collection database. Accordingly, there were found 2219 documents which were published in 332 sources. VOS viewer was employed to portray network analysis of, authorship, keywords visualization, citations, and countries dealing with the subject. SCIMAT software was also used to do longitudinal thematic analysis. Even though many countries, universities, research institutes, funding agencies, and authors contributed for the growth of this field of study, almost all are from developed nations. This study is one amongst the very few studies made using bibliometric analysis in this field. Moreover, the thematic network diagram reveals two other new themes in the subject, which are taken as knowledge seed, and have high potential for a future study.
\end{abstract}

Keywords: SMEs, innovation, SCIMAT and VOSViewer software, bibliometric analysis

\section{Introduction}

Studies showed small and medium-sized enterprises (SMEs) have a paramount importance in accelerating the social and economic development both in developed and developing countries. For instance, as Duncombe (2007) and Nyeko et al. (2013) indicate, employment generation, entrepreneurship, industrial expansion, and export promotions are some of the notable contributions of small and medium enterprises to economic development of countries. SMEs create the foundation of economic growth and social development in all countries around the world in general, and in developing countries in particular (Djebarni and Al-Hyar, 2009). As Abdissa and Fitwi (2016) indicate in their study, 'small and medium enterprises contribute to more than $60 \%$ of GDP and more than $70 \%$ of overall employment in low-economy countries whereas over $95 \%$ of total employment and about 70\% of GDP in middle-income countries'. In the European Union and in the Visegrad countries, the situation is the same; SMEs represent the vast majority of employees and enterprises (SerokaStolka and Jelonek, 2013; Sáez-Martinez et al., 2016; Oláh et al., 2019; Šebestová and Sroka, 2020).

According to Kozan et al. (2006), small and medium enterprises are promoted due to the fact that they are easy to start and simple to operate. In addition to this, the authors indicate the entrepreneurial motives and traits are also among the various reasons to start small businesses. Moreover, Ayyagari et al. (2007) revealed the significance of small and medium enterprises and recommended policy priority specifically in developing countries to reform the policies that divided the formal and informal sector to engage the poor in high value added business.

Today, innovation is considered as a key determinant for organizational competitiveness and success, which exhibits the direction and progress of the regional and the world economic development (Gao et al., 2017). In addition to this, as innovation is a significant element of global competitiveness, efficiency and employment performance, it have several advantages for small and medium enterprises (Lee et al., 2010). Flexibility, rapid response, adaptability to market changes, informal communication coupled with less bureaucracy, rapid decision-making, and greater entrepreneurial spirit are among the primary advantages (Hervas-Oliver et al., 2014) and drive national ecomomies towards economic growth (Braha et al., 2015).

Innovation can also be defined as the methodology of managing, allocating, and timing organizational technology tools, workforce assets, and work processes to achieve a given output in an efficient and expedient manner (Badiru, 2020). The concept of innovation is diversified, depending mainly on its application. According to Contador et al. (2019), innovation is taken as new ideas associated with actions that produce results coated with originality that benefit audience, and measured by their ability to solve issues that are more complex. As innovation is the creation of an enabling environment for people, process, and technology (Kaur and Parneet Kaur, 2020), small and medium enterprises had started to apply information and communication technologies to show their competencies in different economic sectors (Amara and Becheikh, 2006).

Innovation helps to manage businesses in a sustainable way, which will have positive impacts not only on environment, but also on society by improving local communities and local businesses. According to Silvestre (2015) and Maier et al. (2020), innovation is a key mechanism for addressing sustainable development; moreover, innovation can be driven by sustainability (Nidumolu et al., 2009; Ghassim and Bogers, 2019).

Small and medium-sized enterprises are commonly defined as reactive, flexible, and innovative organizations (Expósito and Sanchis-Llopis, 2019). These types of firms usually operate in very competitive markets, and hence the introduction of innovative products, processes, and/or new organizational business models enables them to stand out from the competition, by improving their results and business performance, both in the short- and medium-term. Embracing R\&D and innovation activities is particularly relevant for small and medium enterprises, as these strategies are crucial to productivity growth, firm's competitiveness, and ultimately their survival (Añón-Higón et al., 2014). There is a consensus that small and medium enterprises play a very important role in innovation and almost all small and 
medium enterprises are involved in open innovation compared with large firms (Hossain and Kauranen, 2016).

Due to their size, SMEs lack internal means and resources to coordinate innovation activities which makes them more reliant on open innovation partnerships in their ecosystems (Möller and Janssen, 2009). The study of Liang et al. (2019) also confirms that small and medium enterprises' linkage with other partners has a positive impact on their innovation performance. On the other hand, literature suggests that small and medium enterprises have advantages in that they are often characterized by an entrepreneurial style with lean organizational structures (Klewitz and Hansen, 2014). The study of Hossain and Kauranen (2016) revealed that small and medium enterprises are less bureaucratic, and more flexible for strategy- and decisionmaking, greater risk-taking and knowledge concentrating, and faster reaction to market fluctuations.

Contemporary researchers use the bibliometric research method to discover and examine large volume of information in order to see the patterns of scientific studies made on some specific subject matters (Silva and Teixeira, 2009). Bibliometric approach is very helpful for developing summary of a research field as it pinpoints the top trends by using different bibliometric indicators such as the number of publications and citations, the most influential countries, the most relevant authors, the most prominent institutions supporting research, as well as the citations of papers in major articles (Martínez-López et al., 2020).

Very scant bibliometric studies have been made on the impact of innovation on small and medium enterprises performance. Salvador et al. (2013) conduct a bibliometric analysis on the title 'clustering recent trends in the open innovation literature for small and medium enterprises strategy improvements' and recommended clustering of the key features related with small and medium enterprises. The analysis of Chesbrough and Bogers, (2014) showed an overall classification of researches on innovation without integrating with other research perspectives.

Thus, as a novel contribution, this particular bibliometric analysis examines the trends of scientific studies made by scholars on this subject matter by using bibliometric indicators such as top cited articles, countries dedicated to the subject, journals concentrating on the research area, number of publications with their respective citations, contributing countries, authorship networking, and country networking.

The primary goal of the research was to make a good base for further, empirical researches in relation with the role of innovation as a part of sustainable development of SMEs.

\section{Materials and methods}

The authors developed research questions to make a bibliometric investigation on the effect of innovation on small and medium enterprises. The questions are arranged as follows:

$\square$ Research question 1: How many articles were published on this subject, and who are the main contributors?

$\square$ Research question 2: What are the countries doing to cooperate with Small and Medium Enterprises?

$\square$ Research question 3: Are there top articles referred to and what is the most prominent topic in this subject?

\section{$\square$ Research question 4: What is the major content of the publications?}

One of the most important factors to show how much the researcher is into the topic and its indicator for the expansion of the subject of the study is the growth trend and the number of publications (Ahmed and Huang, 2019;
Udomsap and Hallinger, 2020; Hernández-Torrano and Ibrayeva, 2020; Xie et al., 2020). Top contributors' countries and their social networks show the core focus of the study (Zou et al., 2018; Veloutsou and Mafe, 2020; Peng et al., 2020).

In order to have systematic thinking the visualization and the network come into place (Pauna et al., 2019). VOS viewer is powerful software used for scientific study network analysis (Lawal et al., 2019; Corsi et al., 2020; Yıldı, 2019). The VOS software uses natural language processing (NLP) and provides the clustering, mapping and visualization of the bibliometric networks (van Eck and Waltman, 2010).

The researcher's way to set the direction of the study in the subject of research can be measured through top cited articles; hence, this study uses the top cited article analysis (Hernández-Torrano and Ibrayeva, 2020; Xie et al., 2020; Veloutsou and Mafe, 2020; Martínez-López et al., 2020). To have a deeper inspection in the content of the subject, the keywords analysis is very important, since the keywords are representatives of the publications' context (Veloutsou and Mafe, 2020; Xu et al., 2019). Keywords show the top topic in the area, and the network of the keywords shows the collaboration of the keywords and topics.

The bibliometric information can map a field of science to show the intellectual evolution there (Sharifi, 2020) first studies on'urban sustainability assessment' were published in early 1990s. Since then, the field has grown rapidly, with over 300 papers published annually in recent years. The main objective of this study is to present a bibliometric analysis of about thirty years of research on urban sustainability assessment. The literature database includes 3877 articles published in the Web of Science. VOSviewer and SciMAT are two science mapping software tools that were utilized for this purpose. VOSviewer is utilized to detect major focus areas and to identify influential authors, publications, and journals using various network analysis techniques such as term co-occurrence, co-citation, and bibliographic coupling. Also, SciMAT is used to understand how the intellectual base of the field has evolved over time and what are the major themes that have contributed to this evolution. For this purpose, the study interval was divided into four subperiods (i.e., 1991-2000; 2001-2009; 2010-2015; and 2016-2020. To review the intellectual property of the literature of a science, different methods can be used. The co-word analysis or keyword analysis is one of the main tools to determine the content of a research area (Callon et al., 1991). Keywords in the publication can play the role of the DNA or the fingerprints of research (Börner et al., 2003). The degree of similarity in keywords in publications can show the similarities in them (Börner et al.2003). In 2011, Cobo and his colleagues introduced a strategic diagram mapping showing the thematic network stability between periods, and the thematic evolution techniques for displaying the main themes and content of literature of a science field. For analyzing the conceptual structure of a topic, the co-word analysis is used by scholars (Cobo et al., 2011). Co-keyword analysis is used for mapping the science, whereas the clusters of keywords and their interconnections are identified (Abdi Khalife et al., 2020; Aparicio et al., 2019; López-Robles et al., 2019; Santana and Cobo, 2020; Sharifi, 2020; Xie et al., 2020) first studies on "urban sustainability assessment" were published in early 1990s. Since then, the field has grown rapidly, with over 300 papers published annually in recent years. The main objective of this study is to present a bibliometric analysis of about thirty years of research on urban sustainability assessment. The literature database includes 3877 articles published in the Web of Science. VOSviewer and SciMAT are two science mapping software tools that were utilized for this purpose. VOSviewer is utilized to detect major focus areas and to identify influential authors, publications, and journals using various network analysis techniques such as term co-occurrence, co-citation, and 
bibliographic coupling. Also, SciMAT is used to understand how the intellectual base of the field has evolved over time and what are the major themes that have contributed to this evolution. For this purpose, the study interval was divided into four sub-periods (i.e., 1991-2000; 20012009; 2010-2015; and 2016-2020. Cobo and his team called this cluster the theme of the research. The strategic themes diagram is a twodimensional diagram with four quadrants. This two-dimensional diagram displays the centrality as $x$-axis and density as $y$-axis. This strategic diagram demonstrates the position of different themes in the science in four different quadrants. The analytical result part of this article explains what the position of each theme in each quadrant means. The most significant keyword in each theme is selected as the name of that theme.

In their article, Cobo and his colleagues illustrated the strategic diagram of themes that demonstrate the network of themes (Cobo et al., 2011). They called this network a thematic network that represents the frequency and the relation of the themes in the study field. The size of the spheres represents the number of documents with those themes, while the thickness of the connection lines shows the correlation of those themes.

Two other analyses in the science themes can help to have better understanding of the subject. These two analyses are the stability between periods and thematic evolution. Both of them are analytical indicators of the evolution of the themes of the subject in the past. For this analysis, the time interval should be selected, and the evolution and the changes of the subject can be analyzed by the two graphs (Cobo et al., 2011). Cobo and his colleagues tried to introduce the systematic approach for providing an understanding of the content of the research in the past.

\section{Data collection}

To create an illustrative map of the domain innovation in small and medium enterprises (SMEs) a sample of papers was gathered through one of the most relevant scientific citation databases Web of Science Core Collection database (Diem and Wolter, 2013; Franceschet, 2010; Huertas González-Serrano et al., 2020; Liu, 2013; Soosaraei et al., 2018; Sweileh et al., 2014) particularly Egypt, Kingdom of Saudi Arabia, and Tunisia. However, Kuwait has the highest research productivity per million inhabitants. Main research areas of published documents were in "Food Science/Technology" and "Chemistry" which constituted $75 \%$ of published documents compared with $25 \%$ for worldwide documents in nutrition and dietetics. A total of 329 (15.96\%. The search was performed on September 29, 2020, and saved in the form of "Tab-del: mited (win, utf-8)" for analytical purposes. The period was set to include all available publication years in the Web of Science Core Collection (WSCC) database, which is automatically set from 1976 to 2020 .

This research method (bibliometric technique) is also more suitable for academic field with enormous numbers of publications than qualitative analysis, especially in the study of exploring the internal relationship of the literature. The findings will be based on quantitative statistical analysis and reliable dataset, which generally consists large quantity of peer-reviewed publications that can cover most regions and disciplines and the visualizing network analysis in this method can be used to classify scope and structure of the discipline by discovering the influential authors or papers and main clusters of current research (Ye et al., 2020).

For the purpose of this particular study, two main keywords were employed; the first one is small and medium enterprises and the second one is innovation, and different variations (synonymous) of these two main keywords were used. Full Record, and Cited Reference contents were respectively used for co-authorship and co-occurrence analyses (e.g., network maps of authors, countries, and keywords) and citations analyses (e.g., network map of scientific journals). Thus, 2219 documents were published in 332 sources during the period 1976-2020. These documents were (co)-authored by 4296 authors.

VOS viewer (version 1.6.15) software was used to perform the bibliometric analysis in this study. This software allows for the creation, visualization, and exploration of maps based on bibliometric network data. The output results were displayed in clusters to allow for clear visualization of the existing connections among the bibliometric data.

\section{Results and discussions}

\section{Category visualization}

Articles cover different aspects of research areas: Business economics, Engineering, Operation research management science, Computer science, Public administration, Social science, and Environmental science economy (Figure 1). Web of science assigns indexed papers to one or more research areas. The 2219 considered in our sample were assigned $71.384 \%$ to Business Economics, $12.799 \%$ to Engineering, $9.734 \%$ to Operation research management science, $7.301 \%$ to computer science, and $5.678 \%$ to Public administration.

As for research performance by institutes (Figure 2), the pioneering institute in innovation research, the University of Zhejiang, accounted for the highest number of articles (a Leading University in Asia) in Pro-Innovation Education, Vibrant Research with Impact, Engaging with the World, and Community with Sparkling Ideas. Zhejiang University is one of China's oldest, most selective and most prestigious institutions of higher education. The results match the idea that China is the first country in the number of publications about innovation; followed by the Bucharest University of Economic Studies that is a public university in Bucharest, Romania. It has become one of the largest economic higher education institutes in both Romania and SouthEastern Europe.

The University Sains Malaysia (USM) is also the premium Research Intensive University

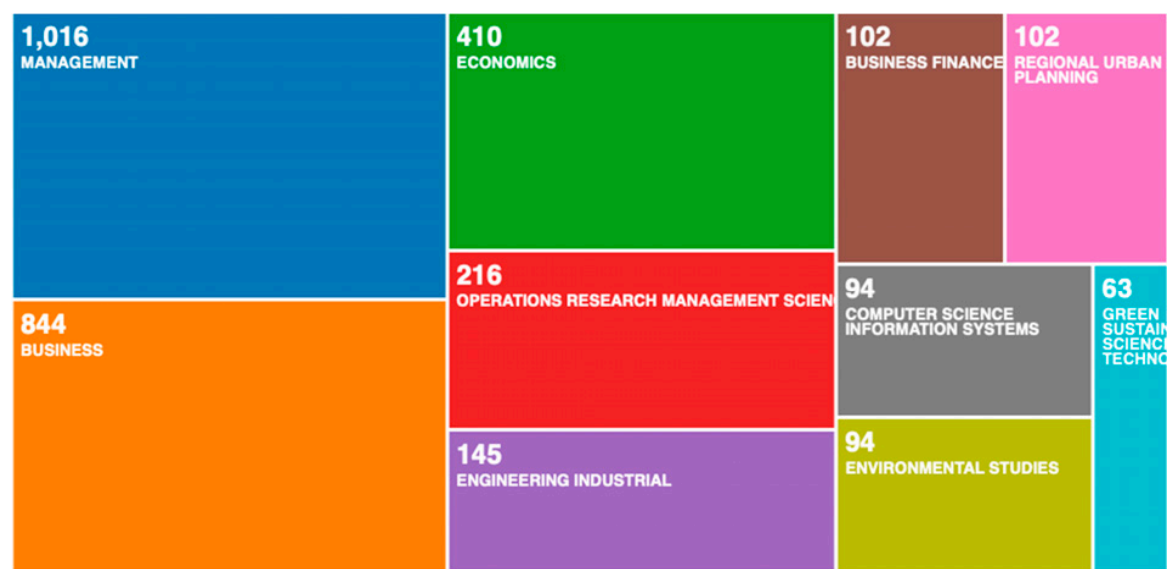

Figure 1 Web of science research categories Source: web of science analysis results 


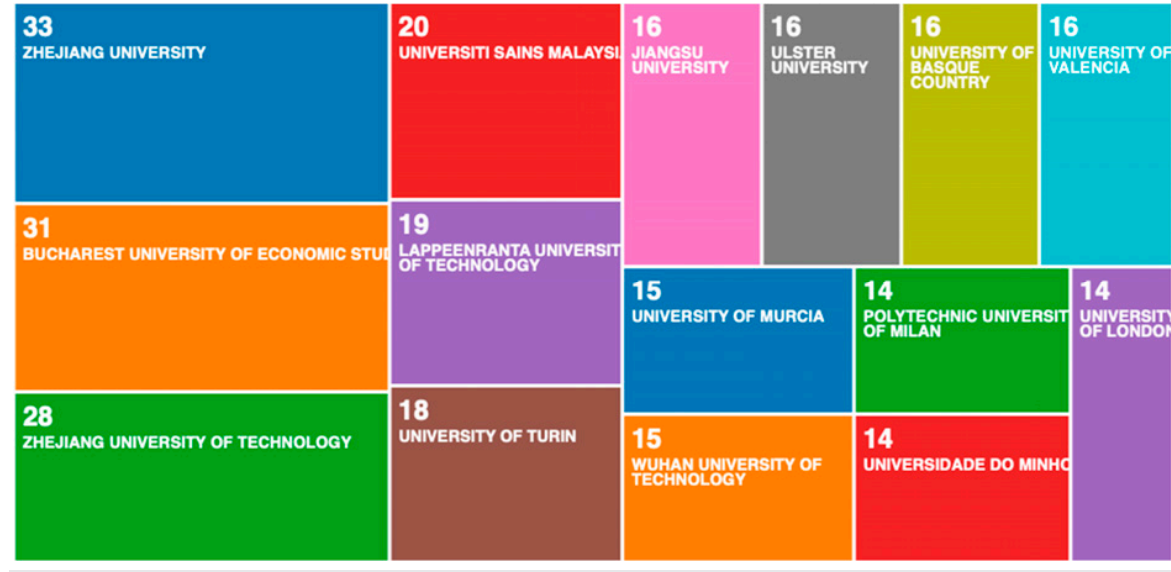

Figure 2 Organization visualization

Source: web of science analysis results

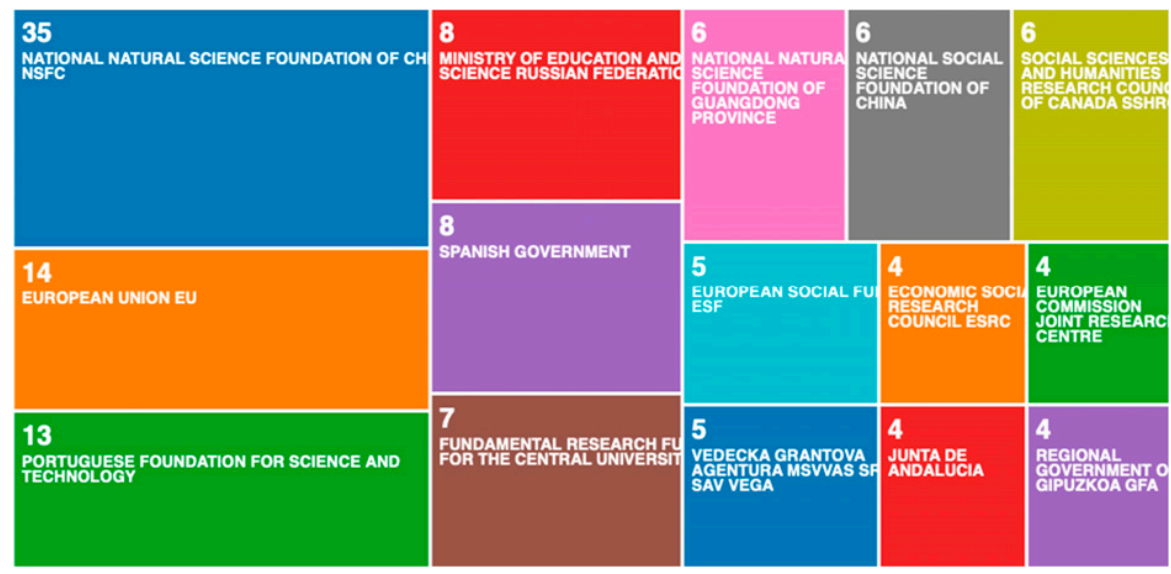

Figure 3 Funding agencies

Source: web of science analysis results
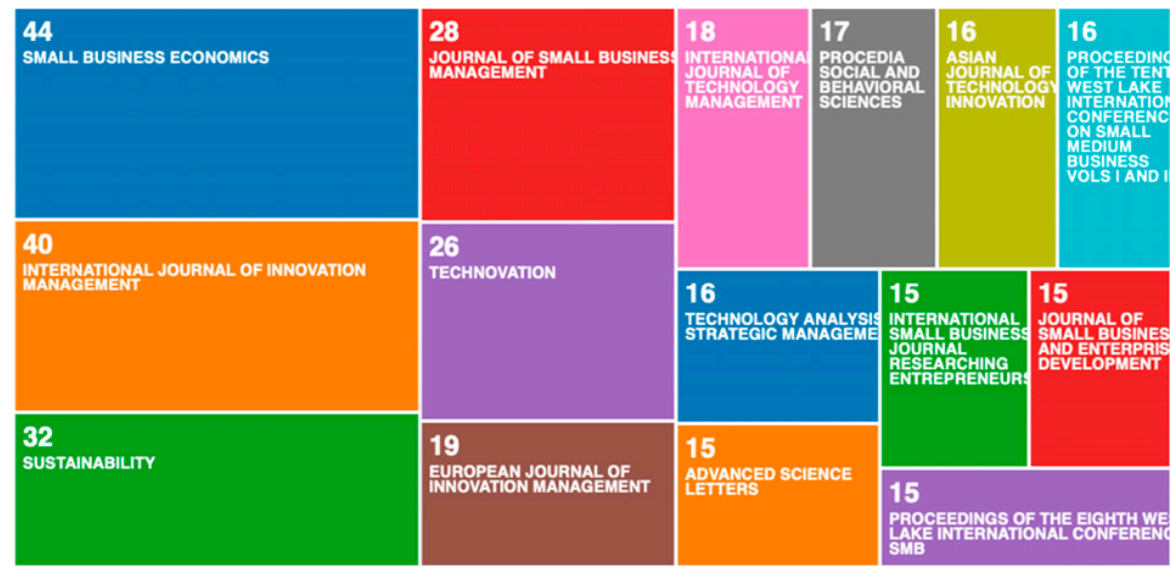

Figure 4 Sources visualization Source: web of science analysis results in the country and has adopted an innovative approach to higher education. It has departed from the traditional faculty system to the broadbased school system. Another university is the Lappeenranta University, a pioneering science university in Finland, bringing together the fields of science and business since 1969.

\section{Funding agencies}

Sometimes searching is about finding trends across a field of study, such as who are the funding agencies for my research. At the top of these agencies there comes a Chinese institution, then the European Union and the Portuguese Foundation for science and technology comes one after the other (Figure 3). So, this finding gives a clue for researchers in this field of study to easily raise a fund from the specified agencies to support their research and publication. One can also take note of these funding agencies affiliation countries promoting the importance of innovation for the efficiency of small and medium enterprises.

Figure 4 shows the ten main sources publishing articles related to Innovation; the sources are journals that reflect the interdisciplinarily of this research field. They include Economics, Business economies, Innovation, Small business management and sustainability. The two leading journals are Small Business Economics and International Journal of Innovation Management.

The common element of all the sources categories in those top ten journals was "small business management", which clearly reflected the close nexus between innovation and the management field. The documents type varies according to Table 1. More than a half of the document type is a journal article, which is $57.323 \%$ of the total document followed by proceeding papers of conferences, and a small portion of the document i.e. $0.315 \%$ is in the form of book.

\section{Trend of publication in web of science core collection}

As for yearly publications, the relative increase was in the years 2008-2009 and 2016-2020. China is the country whose authors have published the most of the documents, followed by England, the United States of America (USA) and Spain.

Figure 5 shows the increase in publications during the years 2016-2019, where SMEs represented the backbone of the economy, and dedicated all efforts to strengthen innovation in SMEs performance to gain competitive advantage and sustainability in the end. 
Table 1 Document type

\begin{tabular}{|l|c|c|}
\hline Document type & Records & \% of total publication(2219) \\
\hline Articles & 1,272 & $57.323 \%$ \\
\hline Proceeding papers & 827 & $37.269 \%$ \\
\hline Book chapter & 117 & $5.273 \%$ \\
\hline Early access & 36 & $1.622 \%$ \\
\hline Editorial material & 34 & $1.532 \%$ \\
\hline Review & 31 & $1.397 \%$ \\
\hline Book review & 26 & $1.172 \%$ \\
\hline Meeting Abstract & 23 & $1.037 \%$ \\
\hline Book & 7 & $0.315 \%$ \\
\hline
\end{tabular}

Source: web of science analysis results

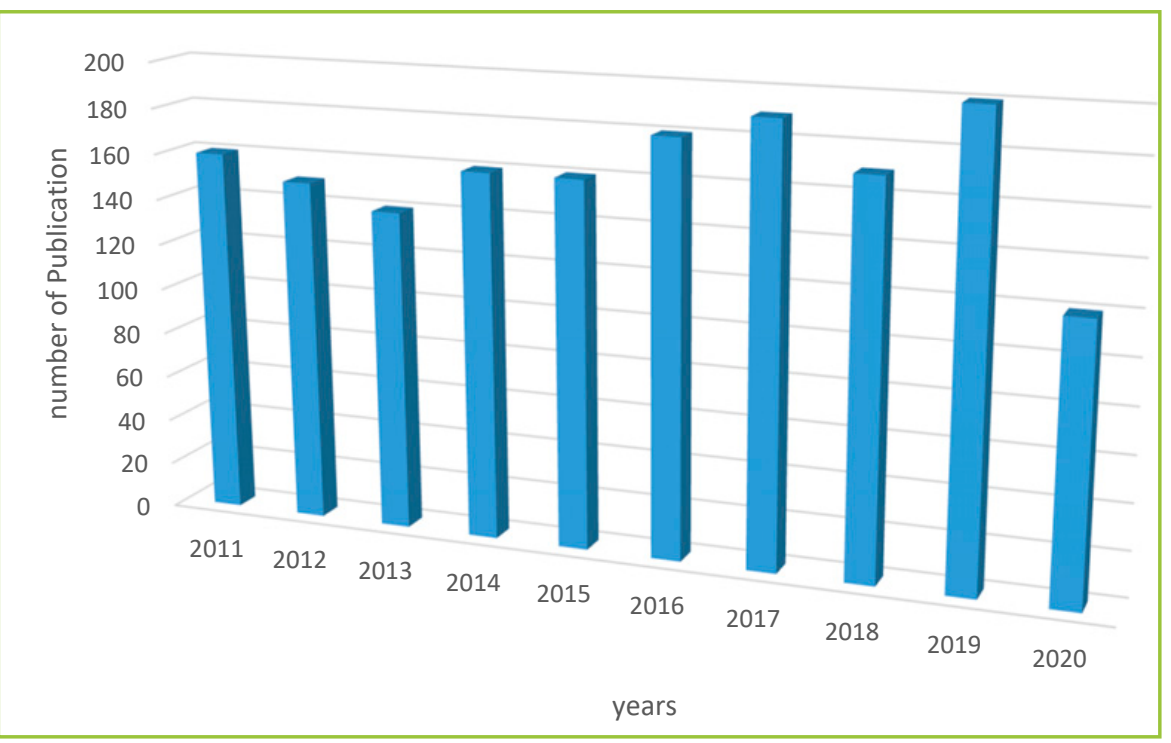

Figure 5 Trends of publications

Source: compiled from VoS viewer

Table 2 Number of publications by country

\begin{tabular}{|l|c|c|}
\hline Countries/region & Number of articles & \% of total publication (2219) \\
\hline China & 420 & 18.927 \\
\hline England & 184 & 8.292 \\
\hline USA & 178 & 8.022 \\
\hline Spain & 175 & 7.886 \\
\hline Italy & 135 & 6.084 \\
\hline France & 82 & 3.695 \\
\hline Malaysia & 77 & 3.470 \\
\hline Germany & 75 & 3.380 \\
\hline Australia & 74 & 3.335 \\
\hline Romania & 66 & 2.974 \\
\hline
\end{tabular}

Source: compiled from VoS viewer
The year 2019 was the most productive with 206 publication; we also observed low growth rate between years 1976 to 1999 , and higher growth rate from 2000 to 2019. The productivity of the publication is increasing over the observed years since 2005 - the rapid decrease in the number of publications in 2020, can be justified by the COVID-19 pandemic and the lockdown situations.

Co-authorship (countries and citation), bibliographic coupling (countries) co-occurrence, and citation analyses conducted to create network maps showing:

1. the co-occurrence of keywords,

2. the co-authorship among researchers and countries,

3. cited scientific journals.

Each network map that resulted from the analyses contains nodes with size determined by "total link strength".

\section{Contributing countries on the impact of Innovation on SMEs}

As for co-authorship countries, the top 10 countries/regions of publications in this field are listed in Table 2 and Figure 6. From Table 2, we can observe China, England, the United States of America (USA), Spain, and Italy as the most contributing countries in which China produces more than two times as much as the others. It is also observed that most of the countries on the list are highly economically dependent on SMEs.

\section{Citation network of countries on the impact of innovation on SMEs}

In the following Table 3 and Figure 7, country's publication cluster and citation networks were examined, respectively. Top 20 countries were categorized into four clusters. Finland, Germany, Indonesia, Malaysia, Portugal, Romania, South Korea, and Spain are included in cluster one, and England, France, China, USA, Australia, and Canada are in cluster 2, and the rest of countries are in cluster 3. It is also observed that most of the countries on the list are highly economically developed countries. This may be due to the active business operations, the cultural background and the high density of academic institutions. The citation networks of different countries were visualized in Figure 7. One can observe from this visualization map that authors from Finland, Germany, Indonesia, Malaysia, Portugal, Romania, South Korea, and Spain are citing each other, which were differentiated by red color in the map. Authors in China, England, the United States of America (USA), Australia, France, and 


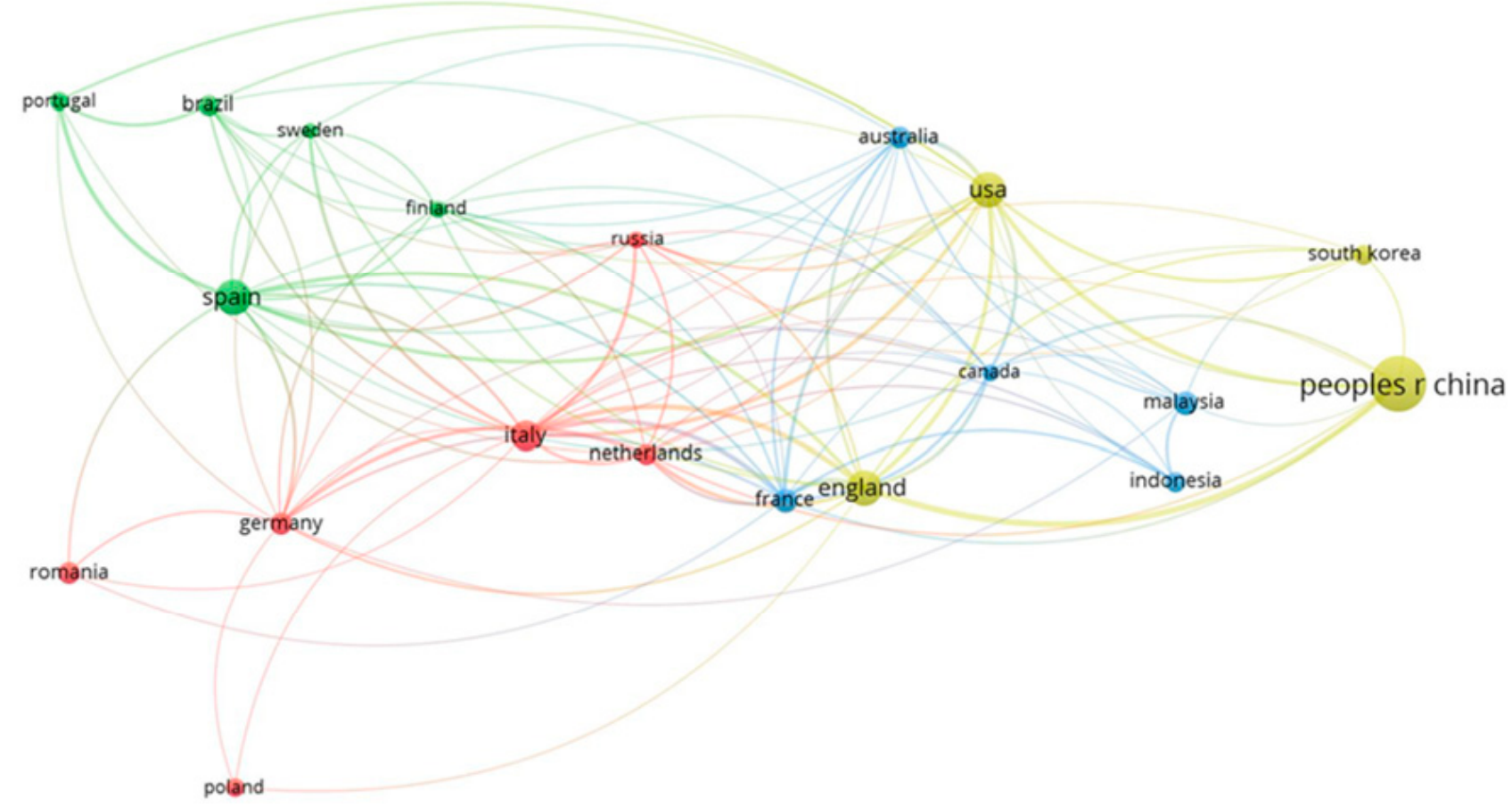

\section{VOSviewer}

Figure 6 Co-Authorship of countries Source: VOS viewer

\section{VOSviewer}

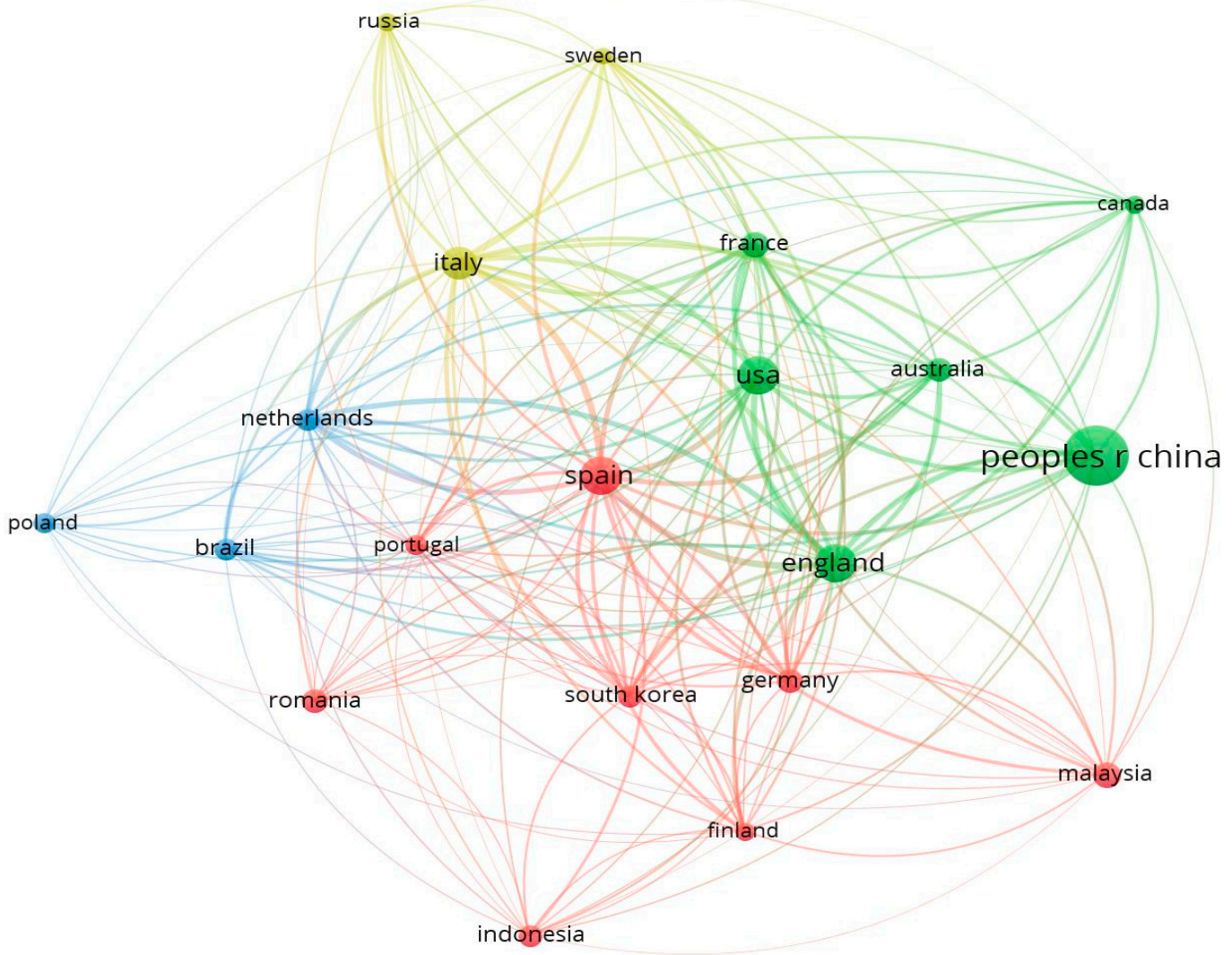

Figure 7 Citation of countries visualization Source: VOS viewer 
Table 3 Number of publications by Country

\begin{tabular}{|l|l|l|l|l|l|c|c|}
\hline Row & Country & Cluster & Number of publication & Row & Country & Number of publication & Cluster \\
\hline $\mathbf{1}$ & Finland & 1 & 41 & 11 & England & 179 & 2 \\
\hline $\mathbf{2}$ & Germany & 1 & 71 & 12 & France & 82 & 2 \\
\hline $\mathbf{3}$ & Indonesia & 1 & 57 & 13 & China & 420 & 2 \\
\hline $\mathbf{4}$ & Malaysia & 1 & 77 & 14 & USA & 170 & 3 \\
\hline $\mathbf{5}$ & Portugal & 1 & 50 & 15 & Brazil & 55 & 3 \\
\hline $\mathbf{6}$ & Romania & 1 & 66 & 16 & Netherland & 58 & 3 \\
\hline $\mathbf{7}$ & South Korea & 1 & 56 & 17 & Poland & 49 & 3 \\
\hline $\mathbf{8}$ & Spain & 1 & 175 & 18 & Italy & 135 & 4 \\
\hline $\mathbf{9}$ & Australia & 2 & 74 & 19 & Russia & 40 & 4 \\
\hline 10 & Canada & 2 & 44 & 20 & Sweden & 34 \\
\hline
\end{tabular}

Source: own completion from VoS viewer

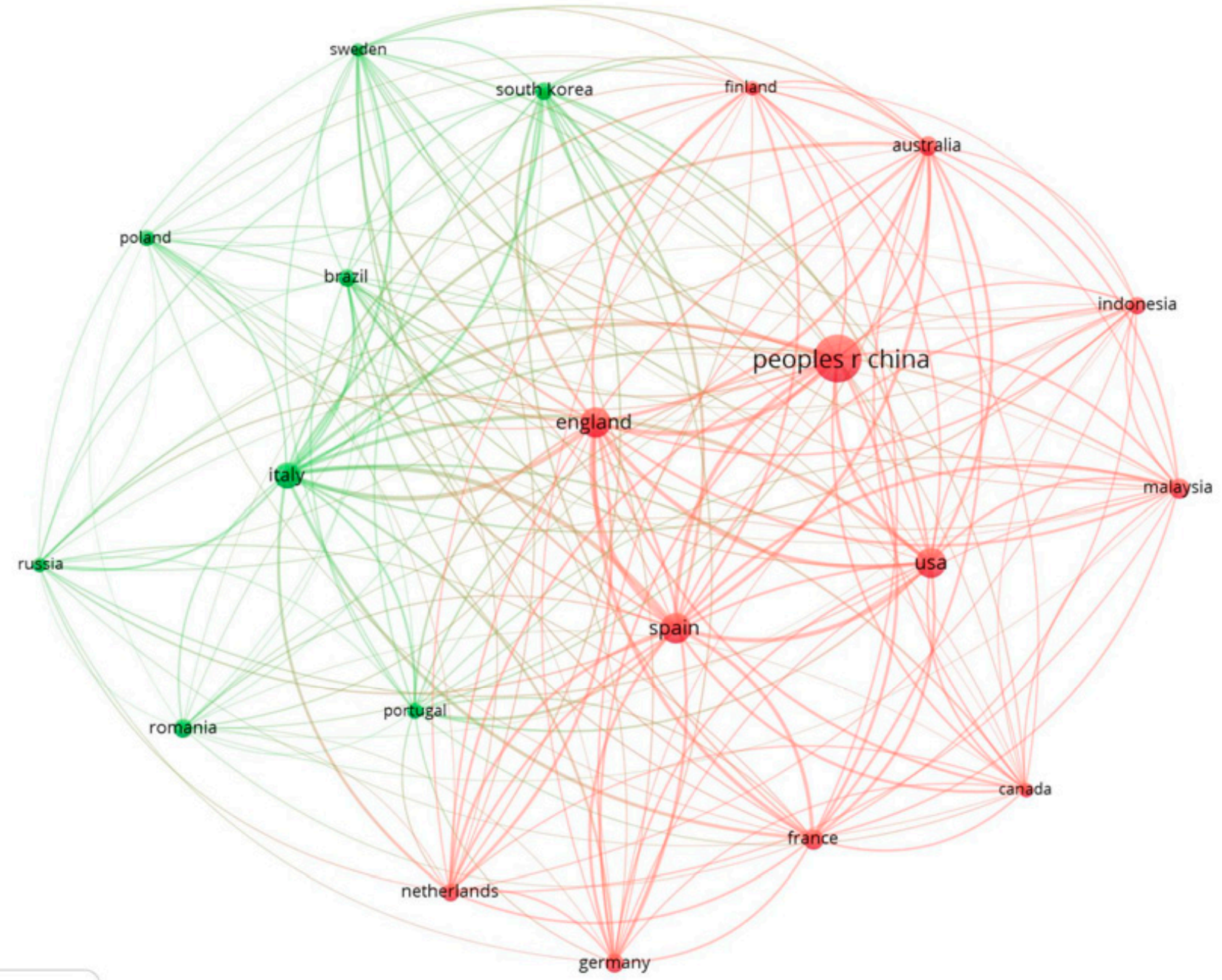

fo vOSviewer

Figure 8 Bibliographic coupling - countries Source: VOS viewer 
Table 4 Keyword Occurrence

\begin{tabular}{|c|c|c|c|c|c|c|c|}
\hline Row & Keyword & Cluster & Occurrence & Row & Keyword & Cluster & Occurrence \\
\hline 1 & absorptive-capacity & 1 & 442 & 16 & knowledge management & 1 & 145 \\
\hline 2 & antecedents & 1 & 221 & 17 & management & 1 & 620 \\
\hline 3 & capabilities & 2 & 398 & 18 & market orientation & 1 & 330 \\
\hline 4 & collaboration & 2 & 346 & 19 & medium-sized enterprises & 3 & 256 \\
\hline 6 & determinants & 3 & 406 & 21 & networks & 2 & 395 \\
\hline 7 & dynamic capabilities & 1 & 271 & 22 & open innovation & 2 & 370 \\
\hline 8 & entrepreneurial orientation & 1 & 245 & 23 & orientation & 1 & 205 \\
\hline 9 & entrepreneurship & 2 & 370 & 24 & performance & 2 & 1,343 \\
\hline 10 & firm performance & 1 & 446 & 25 & product development & 1 & 243 \\
\hline 11 & firms & 2 & 552 & 26 & product innovation & 3 & 382 \\
\hline 12 & growth & 2 & 288 & 27 & research-and-development & 2 & 799 \\
\hline 13 & impact & 1 & 532 & 28 & strategy & 1 & 388 \\
\hline 14 & industry & 2 & 282 & 29 & technological innovation & 3 & 68 \\
\hline 15 & knowledge & 2 & 636 & 30 & technology & 2 & 549 \\
\hline
\end{tabular}

Canada are citing each other i.e. have good citation networks clearly shown by arrows connecting the nodes in yellow color. Authors affiliated to the Netherlands, Brazil, and Poland are networked by blue arrows and citing each other's works.

\section{Bibliographic coupling - countries analysis}

The minimum number of countries, 36 , met the threshold 20 , for each of the 20 countries, the total strength of the bibliographic coupling links with other countries was calculated and the countries with the greatest link strength were selected. As shown in Figure 8, the 20 countries are classified in two clusters identified by the red and green colours. From this Country's analysis, the People's Republic of China, England, USA, and Spain have the greatest linkage with one another, whereas Italy, South Korea, Brazil and Romania have strong bibliographic coupling links.

\section{Key word analysis}

Table 4 summarizes the top 30 keywords in the 2219 articles published on the effect of innovation on small and medium enterprises over the years 19762020. Performance, management, impact, R\&D, knowledge, and technology are the most frequently used keywords, which indicates these terms are topics related to innovation and small and medium sized enterprises performance. The occurrence of group of terms can help to build visualization map to know most important themes of the subject under investigation and the relationship among the keywords. Minimum number of the occurrences of a key word (62) after eliminating 6 keywords are SME, SMEs, Small and medium-sized enterprises, and Small firms.

Co-occurrence of keywords analyzed enabled further interpretation of the information into clusters by using clustering algorithm giving further details on these clusters. A value between 0 and 1 is generally used to measure the internal homogeneity of clusters, or how similar an object is to its own cluster compared to other clusters. Higher values show more effective clustering is formed and the object is well matched within its own cluster. Clustering of keywords indicates that the result of clustering is appropriate to use in analyzing. As was found, different clusters indicated different aspects of innovation issues and concerns over the SMEs operations. Table 4 clusters found represent the major concerns of innovation integration into SMEs.

\section{Top cited articles on the subject}

Table 5 summarizes the top cited articles of Innovation in SMEs in the order from the highest to the lowest. This measure is useful in the sense that separates each article depending on its field and it is a known fact that depends on the field, the number of citations used per article is different. Therefore, it is a good way to highlight important articles from different fields. These papers signalize, in some way, research paths in the literature. From the top cited article; Open innovation in SMEs: Trends, motives and management challenges van de Vrande et al.(2019) multinational enterprises. This exploratory paper investigates if open innovation practices are also applied by small- and medium-sized enterprises (SMEsranked first with 806 total citation and 67.17 citation per year followed by Is innovation always beneficial? A meta-analysis of the relationship between innovation and performance in SMEs Rosenbusch et al.(2011) with 586 total citation and 58.6 citation per year and Open innovation in SMEs - An intermediated network model Lee et al. (2010) with 520 total citation and 47.27 citation per year stand second and third, respectively.

\section{Open innovation in SMEs: trends, motives and management challenges}

This exploratory paper investigates if open innovation practices are applied by small- and medium-sized enterprises (SMEs). Drawing on a database collected from 605 innovative SMEs in the Netherlands, this article with most citation number (806) was published in 2009, which has the peak rate of publications about with $58 \%$ increase in comparison to the previous year.

The second most cited article asks the question whether innovation is always beneficial. It is a meta-analysis of the relationship between innovation and performance in SMEs. This study applies meta-analyses techniques to aggregate prior empirical research on the innovation- 
Table 5 Top cited articles

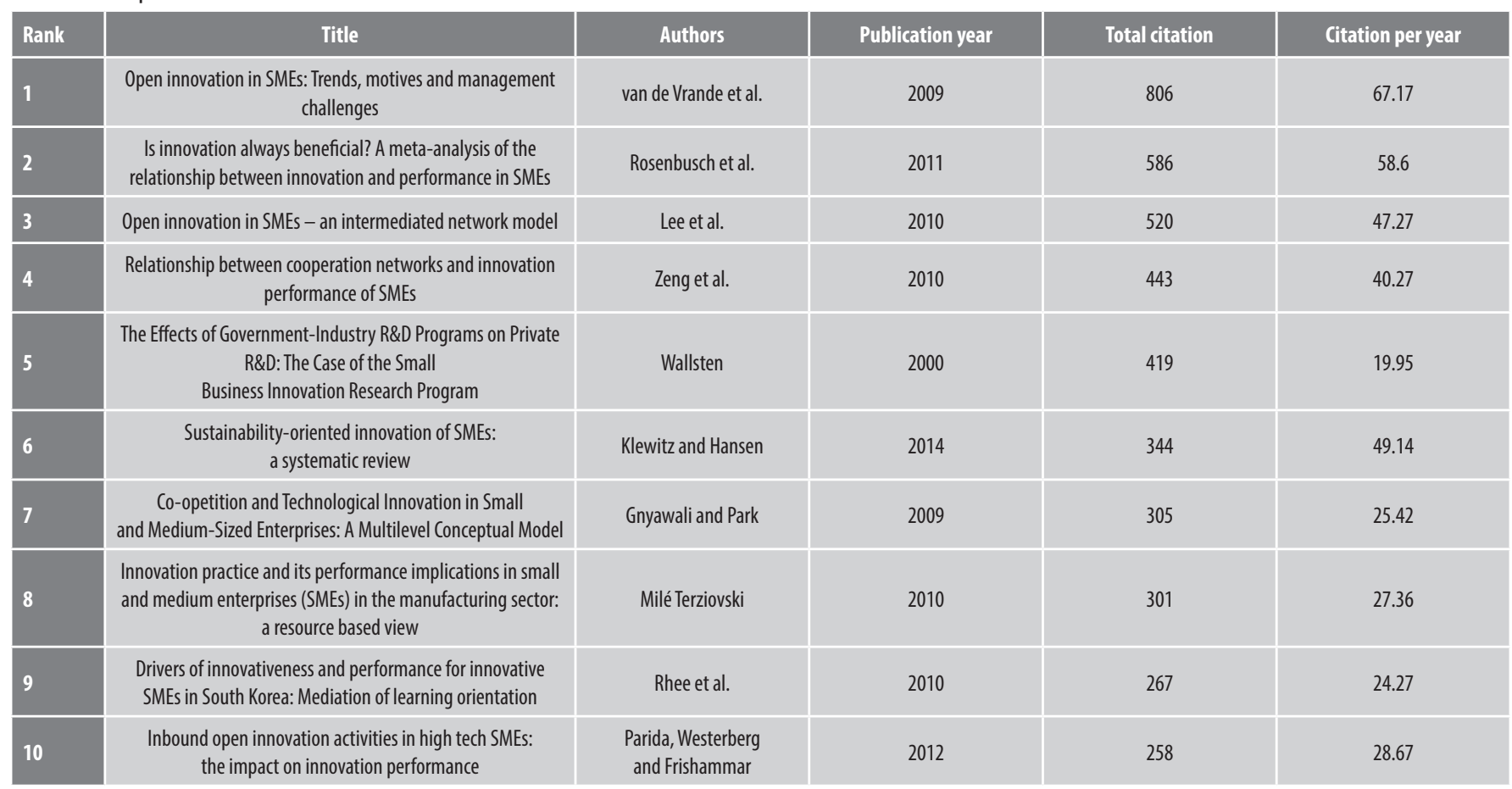

Source: own completion from VoS viewer

performance relationship. It determines the direction and strength of effect innovation has on the performance of small and medium-sized firms (SMEs). Furthermore, the meta-analysis approach allows presenting evidence whether moderators affect the innovation performance relationship. Analysis aggregates 42 empirical studies on 21,270 firms.

\section{Longitudinal thematic analysis}

The collected publications from 1976 to 2020 were dispatched in four periods. The first period from 1976 to 2008 with 357 publications, the second period from 2009 to 2012 with 545 publications, the third period from 2013 to 2016 with 614 publications, and the fourth period from 2017 to 2020 with 703 publications were depicted. The SCIMAT software was used to perform longitudinal thematic analysis on innovation in small and medium size enterprises. For analysis, just the keywords with two times occurrences and more were considered. In addition, the minimum number for the edge of network was set on three. Figure 9 shows the overlapping map for four different periods, in this figure the first circle in the left side represents the first period, which is from 1976 to 2008. The number in the middle of the circle is the number of identified keywords. For the first period, 671 keywords were identified. The number on horizontal arrows that connect the circle of different periods shows the number of similarity of keywords between two periods, and the number in parentheses shows the similarity index. Numbers on upper outgoing arrows is the number of keywords that are not transferred to the next period. For example, in the first period, 416 keywords did not transfer to second period. The numbers on upper incoming arrows show the number of new keywords on that specific period. In this case, for the second period, the number of new keywords is 1010. In reference to Figure 9, the rate of similarity increased through the time,

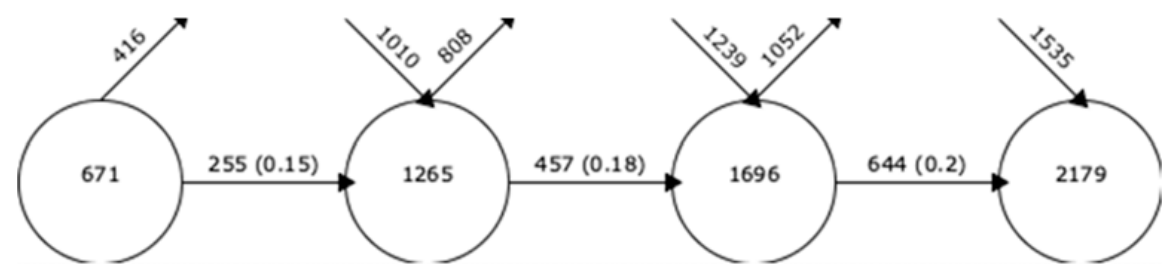

Figure 9 Overlapping map for four period of time, first to fourth period from left to right Source: SCIMAT software

but the increase is not significant and in the last surveyed period (from 2017 to 2020), around third quarters of the keywords are new keywords to the topic. It shows the high rate of changes and evolution in the subject.

Keywords of publications play the role of fingerprints and can characterize the theme of publications. The longitudinal thematic analysis is shown in Figure 10 (Cobo et al., 2011). Table 6 shows the identified themes in different periods.

The first period contains four main themes. These themes are "Innovation, SMEs, Research and development (R\&D), and Knowledge". The first two themes are the search keywords and it is not surprising to see these themes in all four periods. "Research and development" theme is also present in all four periods and it shows the importance of $R \& D$ in innovation in any scale of enterprises. The "knowledge" theme dissolved in the other themes after the second period.

In the second period from 2009 to 2012, ten new themes were indicated. Four of them were exactly the same as in the previous period of time themes and three themes were extracted from the previous themes. These three themes are "Performance, Small firm, and Market orientation". In this period, three new themes were introduced: "Enterprise management, Adaptation, and Systems".

The third period with thirteen themes represents the publications from the 2013-2016 period. Four of these themes are new themes; 
First period 1976 to 2008 I Second period 2009 to | Third period 2013 to 2016 | Fourth period 2017 to 2020

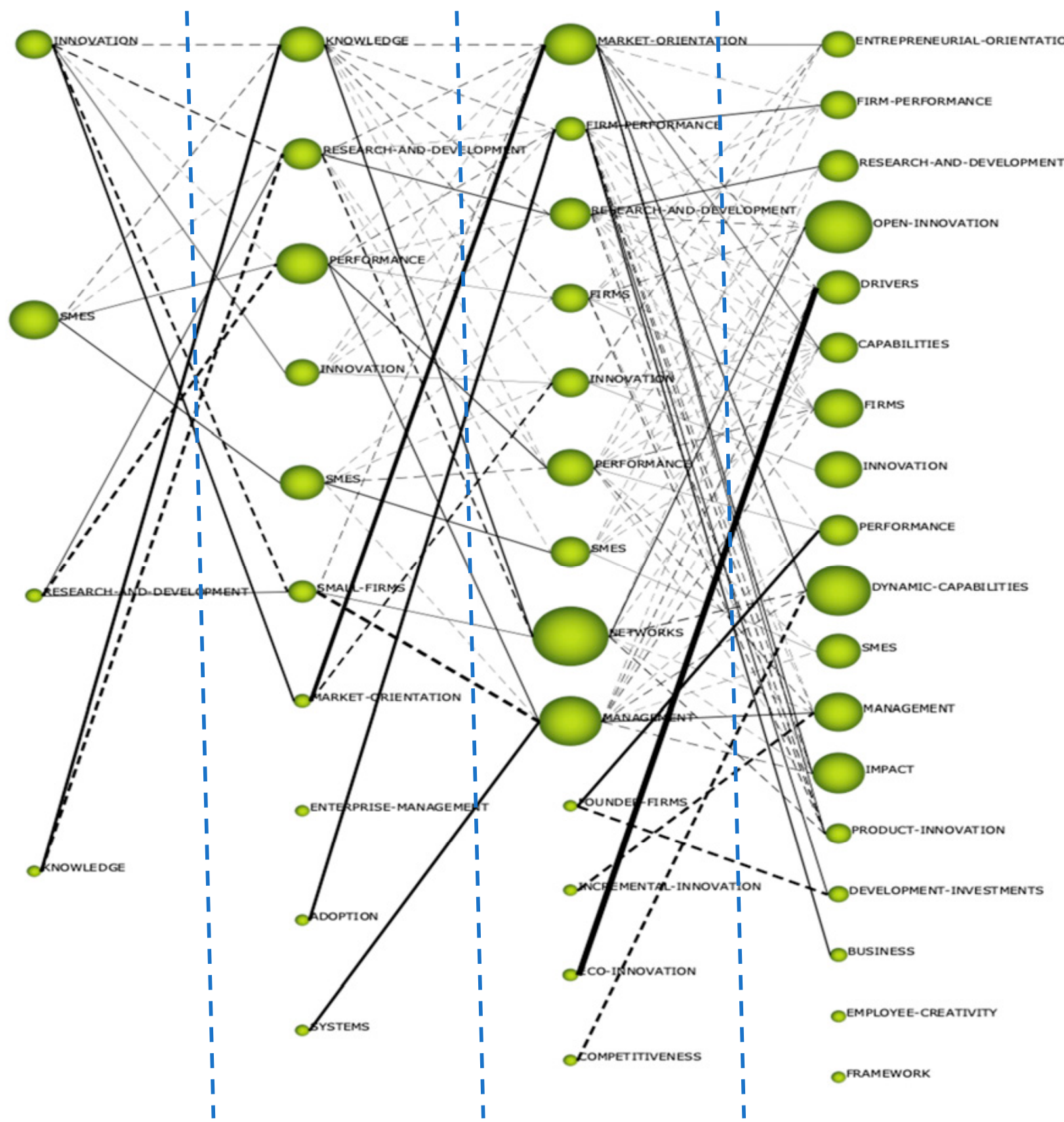

Figure 10 Evolution map for four periods based on documents count (size of each circle based on document count) Source: SCIMAT software

these four themes are "Founder firms, Incremental innovation, Eco innovation, and Competitiveness". The interesting fact is that in this period there are five themes with more than eight connections to the next period of time themes. These themes are "Market orientation, Firm performance, R\&D, Performance, and Management". It shows the connectivity of themes in different periods. The innovation in SMEs subject does not segregate subjects.

The fourth period contains eighteen themes. Just two of these themes are new subjects and all other sixteen are connected to themes of the former periods. These two new themes are "Employee creativity and Framework". The fourth period is the most recent one, and the analysis of the themes in this period shows the most important subject in the research area. The following points were identified in this period: $\square$ "Market orientation" changed to "Entrepreneurial orientation". It seems the entrepreneurial concept became more important than the market need and orientation.

$\square$ "Open innovation" is a new theme with connection to five themes in previous period.

$\square$ "Eco innovation" is the main contributor to the "Drivers" theme in fourth period.

$\square$ "Capabilities and Dynamic capabilities" are two new themes, which are focused on innovation in SMEs capability.

$\square$ "Product innovation" is another new theme.

$\square$ The conversion of "Founder firms" to "Development investments".

$\square$ Introduction of "Business" as a new theme. 
Table 6 Themes in four different periods

\begin{tabular}{|c|c|c|c|c|c|c|c|c|}
\hline \multirow{2}{*}{$\begin{array}{l}\text { Serial } \\
\text { no. }\end{array}$} & \multicolumn{2}{|c|}{ First period: 1977 to 2008} & \multicolumn{2}{|c|}{ Second period: 2009 to 2012} & \multicolumn{2}{|c|}{ Third period: 2013 to 2016} & \multicolumn{2}{|c|}{ Fourth period: 2017 to 2020} \\
\hline & theme & document count & theme & document count & theme & document count & theme & $\begin{array}{l}\text { document } \\
\text { count }\end{array}$ \\
\hline 1 & innovation & 108 & knowledge & 148 & market orientation & 187 & entrepre-neurial orientation & 113 \\
\hline 2 & SMES & 157 & $R \& D$ & 125 & firm performance & 117 & firm performance & 130 \\
\hline 3 & $R \& D$ & 35 & performance & 173 & $R \& D$ & 147 & $R \& D$ & 133 \\
\hline 4 & knowledge & 11 & innovation & 174 & firms & 143 & open innovation & 240 \\
\hline 5 & & & SMES & 275 & innovation & 196 & drivers & 232 \\
\hline 6 & & & small firms & 100 & performance & 180 & capabilities & 154 \\
\hline 7 & & & market orientation & 22 & SMES & 281 & firms & 184 \\
\hline 8 & & & enterprise management & 4 & networks & 271 & innovation & 241 \\
\hline 10 & & & systems & 23 & founder firms & 4 & dynamic capabilities & 268 \\
\hline 11 & & & & & incremental innovation & 6 & SMES & 335 \\
\hline 12 & & & & & eco innovation & 8 & management & 238 \\
\hline 13 & & & & & competitive-ness & 29 & impact & 223 \\
\hline 14 & & & & & & & product innovation & 122 \\
\hline 15 & & & & & & & development investments & 29 \\
\hline 16 & & & & & & & business & 35 \\
\hline 17 & & & & & & & employee creativity & 11 \\
\hline 18 & & & & & & & framework & 25 \\
\hline
\end{tabular}

Document count is a sum-up of primary document count and secondary document count Source: SCIMAT software

Reviewing the longitudinal thematic analysis shows the themes move from general ones such as "Knowledge, Firms, Market orientation, and Management" to more specific themes such as "Entrepreneurial orientation, Open innovation, Dynamic capabilities, and Product innovation". This shift does not push the general themes aside and they still play a role in the field of study.

\section{Strategic diagrams}

The SCIMAT software develops the strategic diagram for each period. The strategic diagram has two-dimensions centrality as $x$-axis and density as $y$-axis. Density shows internal development of each theme and centrality represents the external link of a theme with other themes. There would be four quadrants in strategic diagram and Cobo and his team chose a name for each quadrant (Cobo et al., 2011). Figure 11a shows the strategic diagram for the first period of study from 1976 to 2008 . Figure $11 \mathrm{~b}$ represents the strategic diagram for the second period from 2009 to 2012. The strategic diagram of studies from 2013 to 2016 is figure 11c, and figure 11d is for the last period of study, which is from 2017 to 2020.

"Motor-themes" is the upper-right quadrant developed in both dimensions. The themes in this quadrant are the main backbones of the research field. In the first period, there are no themes in the motor themes quadrant. The "R\&D" is in the y-axis with high density and zero centrality and "innovation" is in the $x$-axis with zero density and medium level on centrality. "Performance and Knowledge" are the two themes in the second period in upper-right quadrant. For the third period of time, "Firm performance, Market orientation, Network and R\&D" are the four themes in this quadrant, and for the fourth period of time "Drivers" is a theme with the highest density, it shows this theme is well-connected to the other themes in the motor-themes quadrant. "Open innovation" presents the highest centrality among this quadrant theme. "Entrepreneurial orientation and firm performance" are two other themes in the upper-right quadrant. The "Dynamic capability" is located in the border of upper-right and a lowerright quadrant, this theme has the highest centrality among all themes and it shows the external development of this theme. All introduced themes play significant roles in innovation in the SMEs topic and are very important for the researchers in this area of study.

Upper-left quadrant shows the themes with high internal strength and low external linkage. "High developed and isolated themes" is the phrase used by Cobo and his team to describe this quadrant (Cobo et al., 2011). The phrase is self-explanatory. For the first period of time, as mentioned, "R\&D" theme demonstrates the highest density, and the "Knowledge" theme is the only member of the upper-left quadrant. In the second period from 2009 to 2012, "Enterprise management" has the highest density as well as lowest centrality. It shows this topic very well internally developed, but it has high potential for external development. Despite its high potential for development, the "Enterprise management" was left behind and no themes were inherited from this theme in the next period of time. "Adoption and market orientation" are two other members of this quadrant for the second period of time.

"Founder firms" presents the highest density not just in this quadrant, but also in the whole third period of time. On the other hand, "Incremental innovation" presents the lowest centrality in this period, and the "Eco innovation" is the other member of this quadrant for the third period of time. The fourth period of time is representative of recent year's studies and 


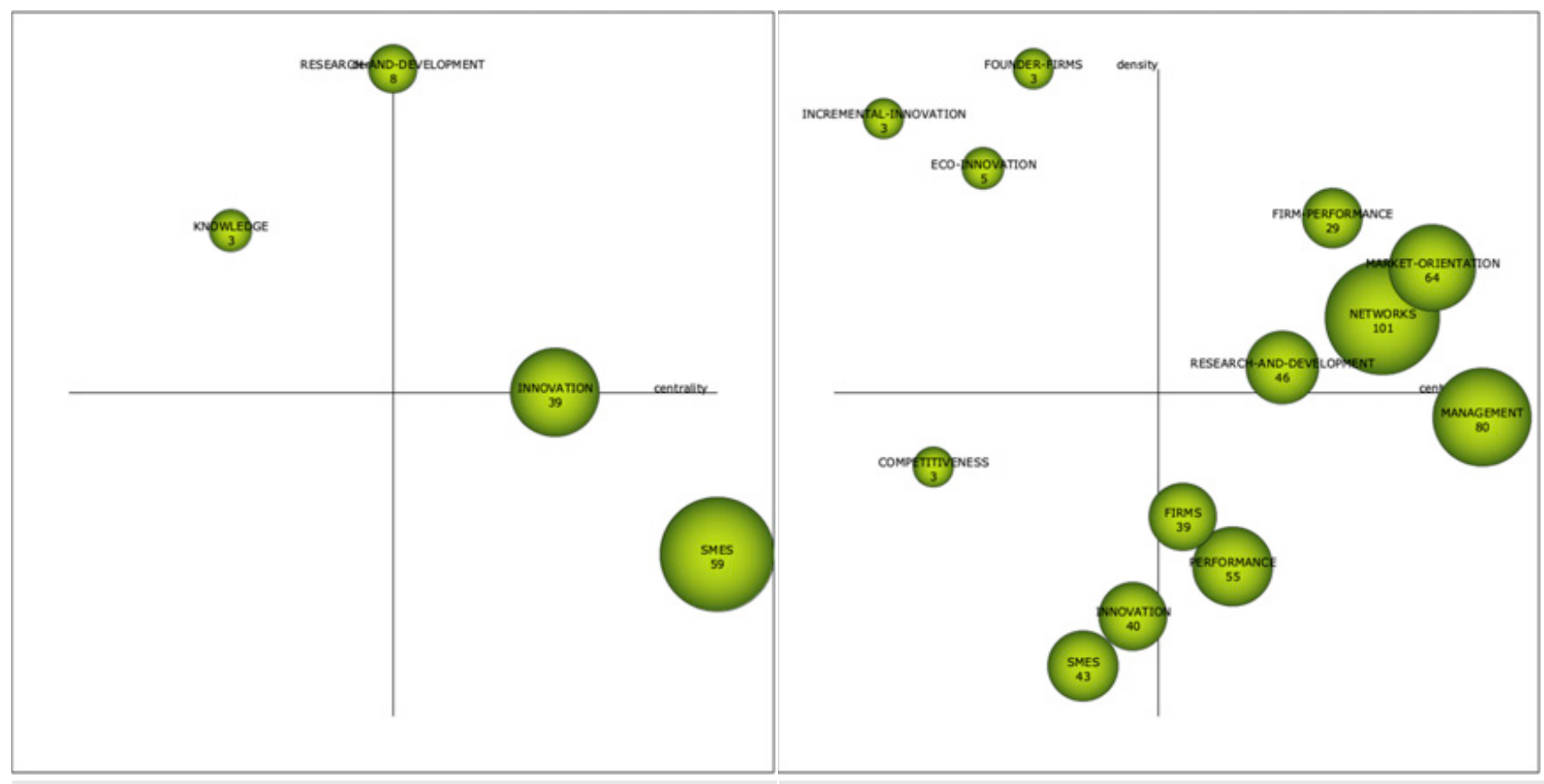

Figure 11a First period strategic diagram

Figure 11c Third period strategic diagram

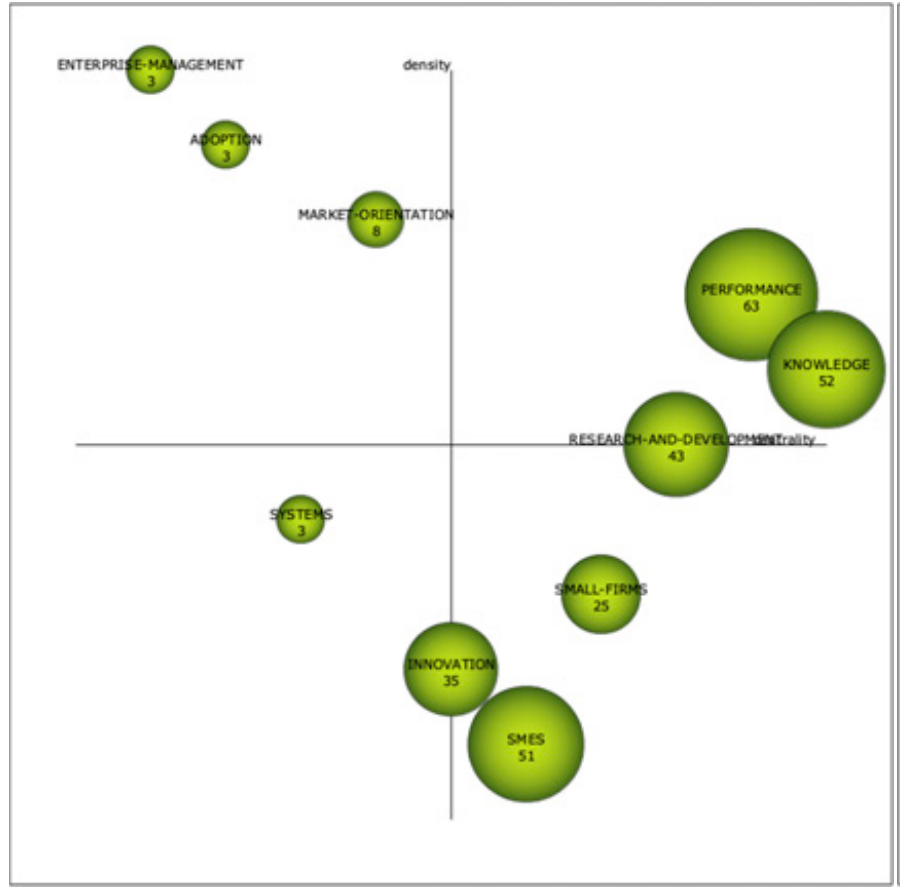

Figure 11b Second period strategic diagram

"Employee creativity" shows the highest density and lowest centrality. This theme may have the same destiny as "Enterprise management" in third period of time or may not. "Founder firms" is antecedent of "Development investments" and both are in the same quadrant. It shows the topic has potential for further discussion and external connection development. "R\&D" moved from upper-right quadrant in the third period to upper-left quadrant in the fourth period of time, it demonstrates that the theme lost its interest for researcher, but it is still very well developed internally. "Framework and Business" are two other themes in this quadrant. Both of themes have potential for future external development.

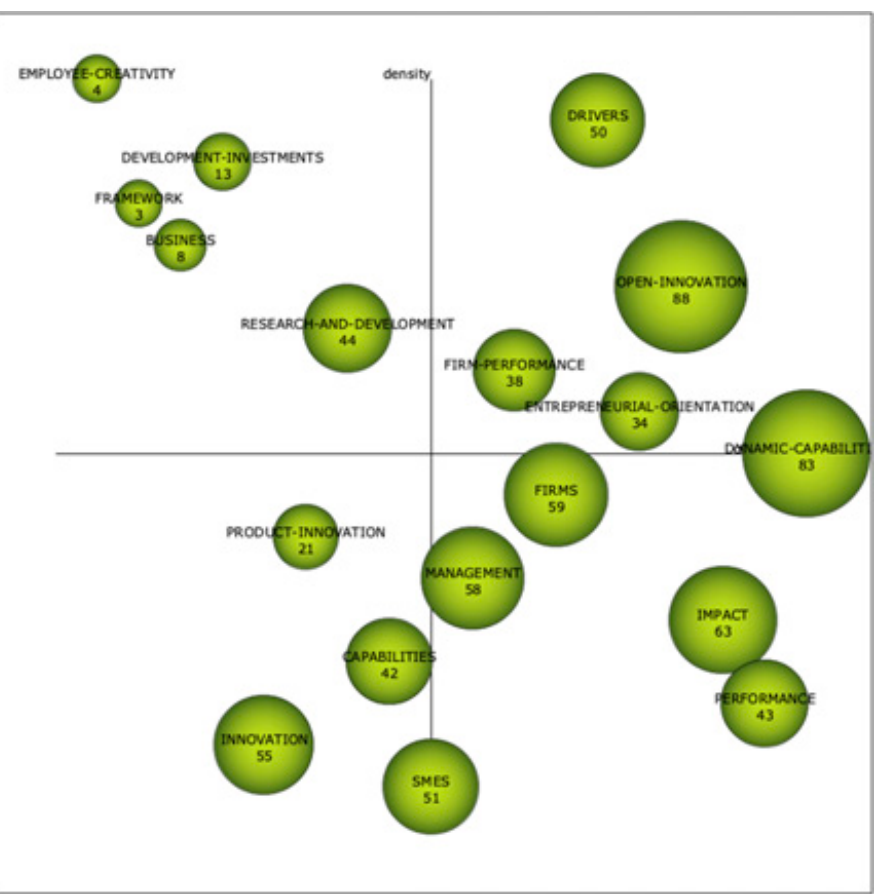

Figure 11d Fourth period strategic diagram

"Basic and transversal themes" are themes with high level of connectivity to the other topic and low level of development. These themes are placed in the lower-right part of the strategic diagram. The themes in this quadrant have high potential for internal development. SMEs and Innovation are two main search keywords and the related themes to these two keywords do not have any meaningful analysis. As it is obvious, these keywords are located in the lower part of the strategic diagram. "SMEs" is the only member of the lower-right part of the diagram for the first period of time. "SMEs" is still in the same quadrant in the second period along with "Small-firms" and Innovation on the density axis in the border for lower-right and lower-left 


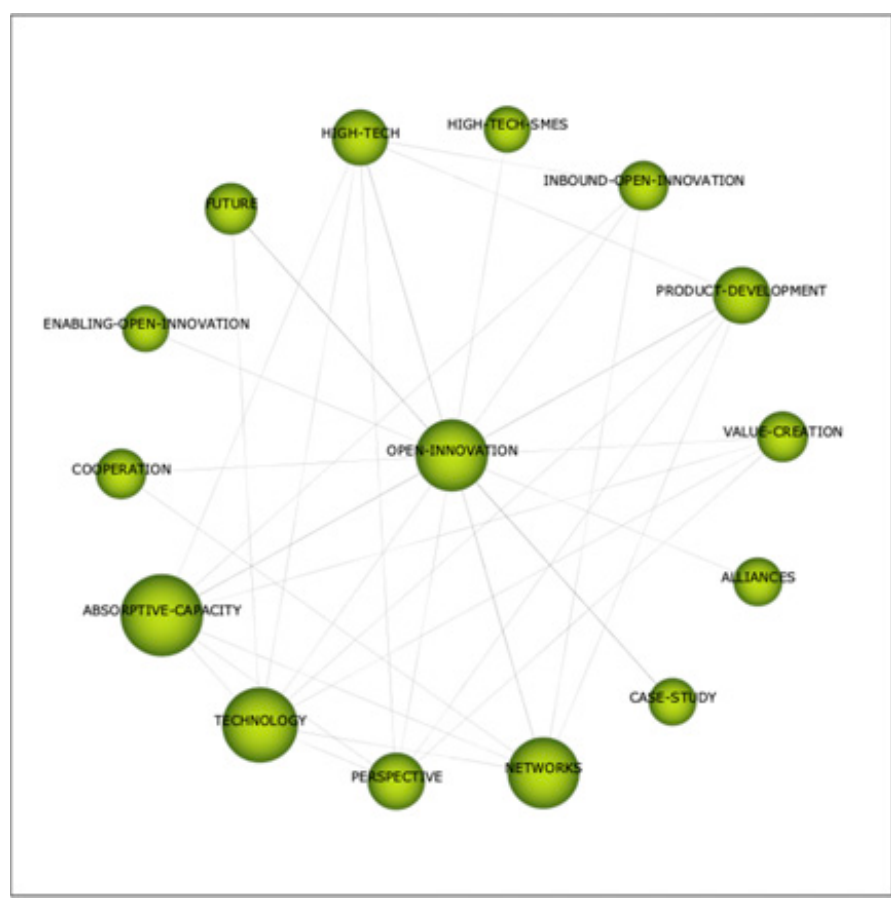

Figure 12a Thematic network of "Open innovation"

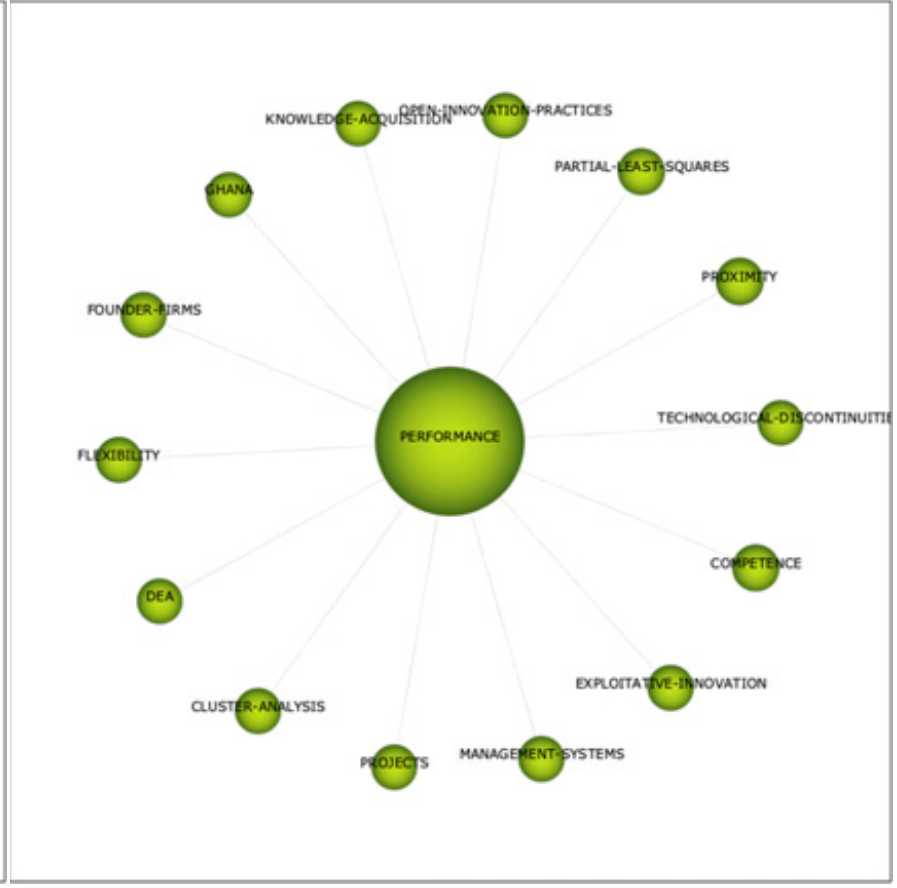

Figure 12c Thematic network of "Performance"

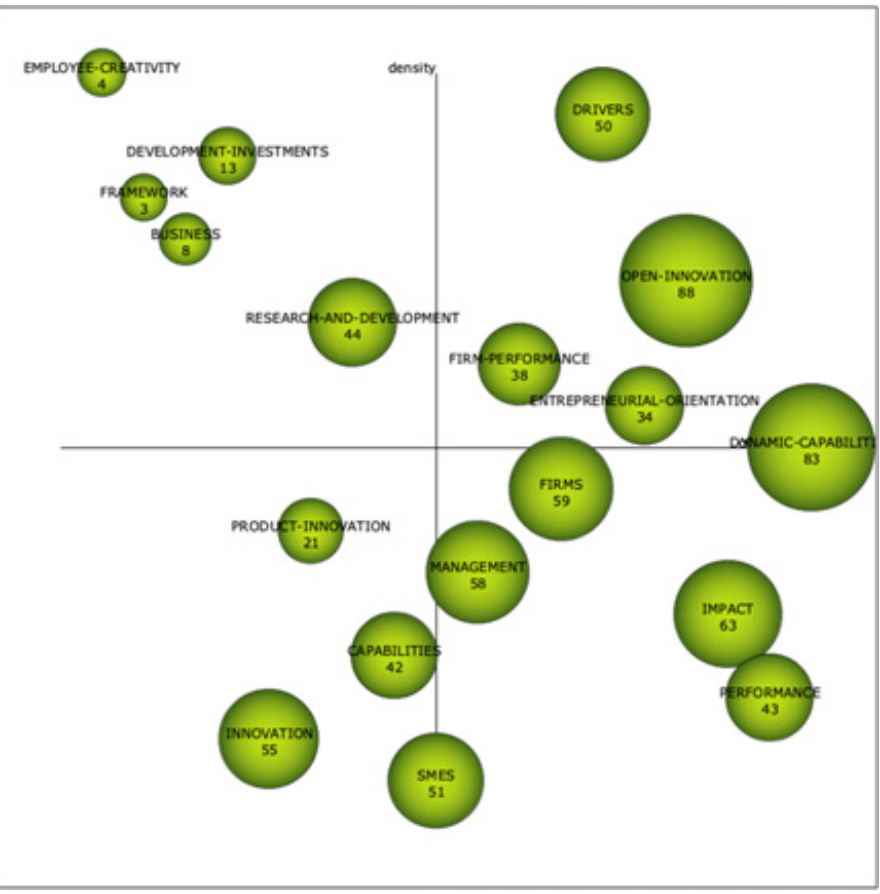

Figure 12d Thematic network of "Product innovation"

this member was "Systems". In the third period of time, two main search keywords "SMEs and Innovation" were in this quadrant along with "Competitiveness". Based on Figure 10, "Competitiveness" contributed to the new theme, which is "Dynamic capability", and the internal and external development of dynamic capability is obvious in the Figure 11d. In the Figure 11d "SMEs and Innovation" themes are still in the lower-left quadrant. Two other themes in this quadrant are "Capability and Product innovation". It seems these two themes are knowledge seeds, and they have high potential for a future study. hence, the name "emerging or declining themes" name was selected this quadrant (Cobo et al., 2011). For the first period of time this quadrant was empty, and for the second period of time it had a solo member and

quadrant. In the third period of time there was "Management" with highest centrality along with "Firms and Performance". All these themes remain in the high potential for internal development for the future research.

The last quadrant is the lower-left quadrant with low level of centrality and density. The themes in this quadrant are either emerging or declining, 


\section{Thematic network}

After the thematic strategic diagram, it is the time for the thematic network. The thematic network for each theme shows the connection of that theme with the other themes and subjects. Figure 12 demonstrates the thematic network; in this figure there are just 12 samples of the thematic network. These are four networks from the fourth period selected, and each of these examples is in a different quadrant. For upper-right quadrant "Open innovation", for upper-left quadrant "Employee creativity", for lower-right quadrant "Performance", and for the lower-left quadrant "Product innovation" were selected. In the thematic network, the size of each circle for the theme shows the number of documents on that theme, and the thickness of the connection lines shows the strength of connection of those themes with the other themes. As it is shown in the Figure 12a, some of these themes around the main theme are also connected to each other, for example "High tech" is connected to "Product development". The themes in the right side of the strategic diagram are well-connected to each other, because the centrality numbers for these themes are higher; Figures $12 \mathrm{a}$ and $12 \mathrm{c}$ present these themes. Themes on the left side of the strategic diagram are less connected, and "employee creativity and product innovation" are two examples coming on Figure $12 \mathrm{~b}$ and Figure $12 \mathrm{~d}$, respectively.

\section{Conclusions}

This paper focused on the effect of innovation in small and medium enterprises by using major indicators of bibliometric analysis to see the growth of the scientific studies in the subject matter. The field showed a rapid scientific growth between the study times (1976-2020) though there are also decreases due to justified reasons. 2219 publication records were extracted from the web of science core collection scientific database in September 2020 , which was produced starting from the commencement of scientific study on the subject. Many countries, universities, research institutes, funding agencies, authors and co-authors contributed to the growth of the field to this level as was clearly explained in the above discussion section of this paper. As observed from the finding, most of the countries contributing to this field of science are developed nations. So, it is also recommended for low-income countries to play their share in contributing in the literature of the subject under study.

Unfortunately, from the Central Eastern European region, only Romania was represented. The lack of the Visegrad Countries in this research is probably reasoned by the low number of journals represented in the WoS, and the fact that many researchers of the Visegrad countries publish in valuable journals of the region and Europe.

In line to the study of Lee et al. (2010) which portrays innovation play great role for small and medium enterprises to sustain, business competitiveness, and employee performance; the current study also highlighted the close nexus between innovation and the management field. The two leading journals (from the top ten publishing journals) of this interdisciplinary research filed are small business economics and international journal of innovation and management, which is the significant evidence for the importance of innovation in the efficiency of small and medium businesses.

Regarding the internalization and collaboration of countries, authors, and co-authorship on innovation and small and medium enterprises, the findings demonstrate remarkable results in the importance of these issues. Bartolacci et al. (2019) recommended that it is better to make a detailed investigation on the importance of collaboration of countries on small and medium firms and innovation in the aim of sharing related benefits and costs. In line with this, the findings showed USA, England, South Korea, and the People's Republic of China as cooperating in one cluster, German, Italy, Romania, Poland, and the Netherlands as collaborating in another cluster, while Malaysia, Indonesia, France, Australia, and Canada collaborate as indicated by arrows connecting the countries differentiated by colour in Figure 6.

Regarding the top cited articles, the article published by Rosenbusch et al. (2009) and van de Vrande et al. (2011) multinational enterprises. This exploratory paper investigates if open innovation practices are also applied by small- and medium-sized enterprises (SMEsare ranked first and second from the top ten cited articles with 67.17 and 58.6 citations per year, respectively. The top cited articles are the most influential publications that attract scientific community toward the subject area. As the finding showed, there is a significant publication growth in the field from 2011 to 2019, which confirms that the subject draws the attention of scholars and practitioners. Publications on this area showed a significant decrease in 2020 due to the fact that almost all researchers do their best to find solutions and recommend some precautions regarding the new pandemic (COVID-19).

Concerning the content of the publication and keyword analysis, performance, knowledge, technology, open innovation, entrepreneurship, management, research and development, and product innovation are the most frequently used keywords and have strong affiliation as indicated in the keyword visualization map. From this output, it can be concluded that these high frequent terms appearing in the keyword visualization map are words that are related to impact of innovation in small and medium enterprises performance, and they may be related to sustainability aspects as well, which is mentioned only indirectly in many sources.

The longitudinal thematic analysis confirms high rate of changes and evolution in the subject. Even though the themes move from such as "Knowledge, firms, market orientation and management" to more specific themes such as "entrepreneurial orientation, open innovation, dynamic capabilities and product innovation", the shift does not push the general themes aside, and they still play a role in the field of study. On the other hand, the thematic network diagram reveals two other themes "Capability and Product innovation" which are taken as knowledge seeds, and they have high potential for a future study. Thus, this study gives an insight for future investigation and has a significant impact to draw attentions of scholars on these newly identified themes in the subject, and as Maier et al (2020) concluded, new field that combines the concepts of innovation and sustainability is rapidly developing.

\section{References}

ABDI KHALIFE, M. - DUNAY, A. - ILLÉS, C. B. 2020. Bibliometric Analysis of Articles on Project Management Research. Periodica Polytechnica Social and Management Sciences, 1-14. https://doi.org/10.3311/ppso.15717

ABDISSA, G. - FITWI, T. 2016. Factors Affecting Performance of Micro and Small Enterprises in South West Ethiopia: The Case of Bench Maji, Sheka, and Kefa Zones. In Global Journal of Management and Business Research : Administration and Management, vol. 16, 2016, no. 10, pp. 46-64.

AHMED, S. - HUANG, B. 2019. Control engineering practice in 25 years: A bibliometric overview. In Control Engineering Practice, vol. 88, 2019, pp. 16-20.

AMARA, N. - BECHEIKH, N. 2006. Lessons from innovation empirical studies in the manufacturing sector: A systematic review of the literature from 1993-2003. In Technovation, vol. 26, 2009, no. 5-6, pp. 644-664. https://doi.org/10.1016/j. technovation.2005.06.016

AÑÓN-HIGÓN, D. - ANTOLIN, M. M. - MAÑEZ, J. A. - SANCHIS-LLOPIS, J. A. 2014. Does $R \& D$ protect SMEs from the hardness of the cycle? Evidence from Spanish SMEs 
(1990-2009). In International Entrepreneurship and Management Journal (IEMJ), vol. 3, 2014, pp. 361-376.

APARICIO, G. - ITURRALDE, T. - MASEDA, A. 2019. Conceptual structure and perspectives on entrepreneurship education research: A bibliometric review. In European Research on Management and Business Economics, vol. 25, 2019, no. 3, pp. 105-113. https://doi.org/10.1016/j.iedeen.2019.04.003

AYYAGARI, M. - BECK, T. - DEMIRGUC-KUNT, A. 2007. Small and medium enterprises across the globe. In Small Business Economics, vol. 29, 2007, no. 4, pp. 415-434. https://doi.org/10.1007/s11187-006-9002-5

BADIRU, A. B. 2020. Innovation System approach. Boca Raton: CRC Press, 2020.

BARTOLACCI, F. - DEL GOBBO, R. - PAOLINI, A. - SOVERCHIA, M. 2019. Efficiency in waste management companies: A proposal to assess scale economies. In Resources, Conservation and Recycling, vol. 148, 2019, pp. 124-131. https://doi.org/10.1016/j. resconrec.2019.05.019

BÖRNER, K. - CHEN, C. - BOYACK, K. W. 2003. Visualizing knowledge domains. In Annual Review of Information Science and Technology, vol. 37, 179-255. https://doi.org/10.1002/aris.1440370106

BRAHA, K. - QINETI, A. - SERENČÉŠ, R. 2015. Innovation and Economic Growth: The Case Of Slovakia. In Visegrad Journal on Bioeconomy and Sustainable Development, vol. 4, 2015, no. 1, pp.7-13. https://doi.org/10.1515/vibsd-2015-0002

CALLON, M. - COURTIAL, J. P. - LAVILLE, F. 1991. Co-word analysis as a tool for describing the network of interactions between basic and technological research: The case of polymer chemsitry. In Scientometrics, vol. 22, 1991, no. 1, pp. 155-205. https://doi.org/10.1007/BF02019280

CHESBROUGH, H. - BOGERS, M. 2014. Explicating Open Innovation: Clarifying an Emerging Paradigm for Understanding Innovation Keywords. New Frontiers in Open Innovation, 2014, 1-37.http://papers.ssrn.com/sol3/Papers.cfm?abstract id=2427233

COBO, M. J. - LÓPEZ-HERRERA, A. G. - HERRERA-VIEDMA, E. - HERRERA, F. 2011. An approach for detecting, quantifying, and visualizing the evolution of a research field: A practical application to the Fuzzy Sets Theory field. In Journal of Informetrics, vol. 5, 2011, no. 1, pp. 146-166. https://doi.org/10.1016/j.joi.2010.10.002

CONTADOR, J. L. - CONTADOR, J. C. - de OLIVEIRA, P. P. - SÁTYRO, W. C. 2019. Entrepreneurship, innovation and growth in different types. In Revista Pensamento Contemporâneo em Administração, vol. 13, 2019, no. 4, pp. 17-35.

CORSI, A. - PAGANI, R. N. - KOVALESKI, J. L. - da SILVA, V. L. 2020. Technology transfer for sustainable development: Social impacts depicted and some other answers to a few questions. In Journal of Cleaner Production, vol. 245, 2020.

DIEM, A. - WOLTER, S. C. 2013. The Use of Bibliometrics to Measure Research Performance in Education Sciences. In Research in Higher Education, vol. 54, 2013, no. 1, pp. 86114. https://doi.org/10.1007/s11162-012-9264-5

DJEBARNI, R. - AL-HYAR, K. 2009. Exporting barriers and the internationalisation of manufacturing activities by SMEs in Jordan. Seoul, Korea, International Council for Small business (ICSB), 2009, pp. 1-22.

DUNCOMBE, R. 2007. Using the Livelihoods Framework to Analyze ICT Applications for Poverty Reduction through Microenterprise. In The Massachusetts Institute of Technologylnformation Technologies and International Developmen, vol. 3, 2007, no. 3, pp. 81-100.

EXPÓSITO, A. - SANCHIS-LLOPIS, J. A. 2019. The relationship between types of innovation and SMEs' performance: a multi-dimensional empirical assessment. In Eurasian Business Review, 2019, pp. 115-135.

FRANCESCHET, M. 2010. A comparison of bibliometric indicators for computer science scholars and journals on Web of Science and Google Scholar. In Scientometrics, vol. 83, 2010, no. 1, pp. 243-258. https://doi.org/10.1007/s11192-009-0021-2

GAO, D. - XU, Z. - RUAN, Y. Z. - LU, H. 2017. From a systematic literature review to integrated definition for sustainable supply chain innovation (SSCI). In Journal of Cleaner Production, vol. 142, 2017, no. 4, pp. 1518-1538.

GHASSIM, B. - BOGERS, M. 2019. Linking stakeholder engagement to profitability through sustainability-oriented innovation: A quantitative study of the minerals industry. In Journal of Cleaner Production, vol. 224, 2019, pp. 905-919.

GNYAWALI, D. R. - PARK, B. R. 2009. A Multilevel Conceptual Model. In Journal of Small Business Management, vol. 47, 2009, no. 3, pp. 308-330.

HERNÁNDEZ-TORRANO, D. - IBRAYEVA, L. 2020. Creativity and education: A bibliometric mapping of the research literature (1975-2019). In Thinking skills and creativity, vol. $35,2020$.

HERVAS-OLIVER, J.-L. - SEMPERE-RIPOLL, F. - MOLL, C. B. 2014. Process innovation strategy in SMEs, organizational innovation and performance: a misleading debate? In Small Bus Econ, vol. 43, 2014, no. 4, pp. 873-886.
HOSSAIN, M. - KAURANEN, I. 2016. Open innovation in SMEs: a systematic literature review. In Journal of Strategy and Management, vol. 9, 2016, no. 1, pp. 58-73. https://doi.org/10.1108/JSMA-08-2014-0072

HUERTAS GONZÁLEZ-SERRANO, M. - JONES, P. - LLANOS-CONTRERA, 0. 2020. An overview of sport entrepreneurship field: a bibliometric analysis of the articles published in the Web of Science. In Sport in Society, vol. 23, 2020, no. 2, pp. 296-314. https://doi.org/10.1080/17430437.2019.1607307

KAUR, N. - PARNEET, K. 2020. What drives innovation in micro, small, and medium enterprises? In Journal of Public Affair, 2020.

KLEWITZ, J. - HANSEN, E. G. 2014. Sustainability-oriented innovation of SMEs: A systematic review. In Journal of Cleaner Production, vol. 65, 2014, pp. 57-75. https://doi.org/10.1016/i.jclepro.2013.07.017

KOZAN, M. K. - ÖKSOY, D. - ÖZSOY, 0. 2006. Growth plans of small businesses in Turkey: Individual and environmental influences. Journal of Small Business Management, 44(1), 114-129. https://doi.org/10.1111/j.1540-627X.2006.00157.x

LAWAL, I. A. - KLINK, M. - NDUNGU, P. - MOODLEY, B. 2019. Brief bibliometric analysis of "ionic liquid" applications and its review as a substitute for common adsorbent modifier for the adsorption of organic pollutants. In Environmental Research, vol. 175, 2019, pp. 34-51.

LEE, S. - PARK, G. - YOON, B. - PARK, J. 2010. Open innovation in SMEs - An intermediated network model. In Research Policy, vol. 39, 2010, no. 2, pp. 290-300. https://doi.org/10.1016/j.respol.2009.12.009

LIANG, M. - ZHANG, T. - CHEN, J. 2019. Exploring the effects of inter-firm linkages on SMEs' open innovation from an ecosystem perspective: An empirical study of Chinese manufacturing SMEs. In Technological Forecasting and Social Change, vol. 144, 2019, pp. $118-128$

LIU, X. 2013. Full-Text Citation Analysis: A New Method to Enhance. In Journal of the American Society for Information Science and Technology, vol. 64, 2013, pp. 18521863. https://doi.org/10.1002/asi

LÓPEZ-ROBLES, J. R. - RODRÍGUEZ-SALVADOR, M. - GAMBOA-ROSALES, N. K. RAMIREZ-ROSALES, S. - COBO, M. J. 2019. The last five years of Big Data Research in Economics, Econometrics and Finance: Identification and conceptual analysis. In Procedia Computer Science, vol. 162, 2019, pp. 729-736. https://doi.org/10.1016/i. procs.2019.12.044

MAIER, D. - MAIER, A. - AȘCHILEAN, I. - ANASTASIU, L. - GAVRIȘ, 0. 2020.The Relationship between Innovation and Sustainability: A Bibliometric Review of the Literature. In Sustainability, vol. 12, 2020, no. 10, pp. 4083. https://doi.org/10.3390/ su12104083

MARTíNEZ-LÓPEZ, F. J. - MERIGÓ, J. M. - GÁZQUEZ-ABAD, J. C. - RUIZ-REAL, J. L. 2020. Industrial marketing management: Bibliometric overview since its foundation. In Industrial Marketing Management, vol. 84, 2020, pp. 19-38.

MÖLLER, K. - JANSSEN, S. H. 2009. Innovation Performance Measurement. In Controlling, vol. 21, 2009, no. 2, pp. 89-96. https://doi.org/10.15358/0935-0381-2009-2-89

NIDUMOLU, R. - PRAHALAD, C.K. - RANGASWAMI, M.R. 2009. Why sustainability is now the key driver of innovation. In Harvard Business Review, vol. 87, 2009, pp. 56-64.

NYEKO, S. - KABAALE, E. - MOYA, M. - AMULEN, C. - KITUYI, G. M. 2013. The Role of Information Communication Technology (ICT) Small and Medium Enterprises (SMEs) in Job Creation in Kampala, Uganda. In Journal of Business Management and Administration, vol. 1, 2013, no. 5, pp. 75-82.

OLÁH, J. - KOVÁCS, S. - VIRGLEROVA, Z. - LAKNER, Z. - KOVACOVA, M. - POPP, J. 2019. Analysis and Comparison of Economic and Financial Risk Sources in SMEs of the Visegrad Group and Serbia. In Sustainability, vol. 11, 2019, no. 7, pp. 1853. https://doi.org/10.3390/su11071853

PAUNA, V. et al. 2019. The issue of microplastics in marine ecosystems: A bibliometric network analysis. In Marine Pollution Bulletin, vol. 149, 2019.

PENG, R.-Z. - CHONGGUANG, Z. - WU, W.-P. 2020. Visualizing the knowledge domain of intercultural competence research: A bibliometric analysis. In International Journal of Intercultural Relations, 2020, pp. 58-68.

RHEE, J. - PARK, T. - LEE, D. H. 2010. Drivers of innovativeness and performance for innovative SMEs in South Korea: Mediation of learning orientation. In Technovation, vol. 30, 2010, no. 1, pp. 65-75. https://doi.org/10.1016/j.technovation.2009.04.008

ROSENBUSCH, N. - BRINCKMANN, J. - BAUSCH, A. 2011. Is innovation always beneficial? A meta-analysis of the relationship between innovation and performance in SMEs. In Journal of Business Venturing, vol. 26, 2011, no. 4, pp. 441-457. https://doi.org/10.1016/i.jbusvent.2009.12.002

SÁEZ-MARTíNEZ, F. - DÍAZ-GARCÍA, C. - GONZÁLEZ-MORENO, Á. 2016. Factors Promoting Environmental Responsibility in European SMEs: The Effect on Performance. In Sustainability, vol. 8, 2016, no. 9, pp. 898. https://doi.org/10.3390/su8090898 
SALVADOR, E. - MONTAGNA, F. - MARCOLIN, F. 2013. Clustering recent trends in the open innovation literature for SME strategy improvements. In International Journal of Technology, Policy and Management, vol. 13, 2013, no. 4, pp. 354-376. https://doi.org/10.1504/IJTPM.2013.056788

SANTANA, M. - COBO, M. J. 2020. What is the future of work? A science mapping analysis. In European Management Journal, vol. 38, 2020, no. 6, pp. 846-862. https://doi. org/10.1016/j.emj.2020.04.010

ŠEBESTOVÁ, J. - SROKA, W. 2020. Sustainable development goals and SMEs decisions: Czech Republic vs. Poland. In Journal of Eastern European and Central Asian Research (JEECAR), vol. 7, 2020, no. 1, pp. 39-50. https://doi.org/10.15549/jeecar.v7i1.418

SEROKA-STOLKA, O. - JELONEK, D. 2013. Environmental Awareness and the Best Environmental Practices in SME of the Food Industry in the Częstochowa Region. In Visegrad Journal on Bioeconomy and Sustainable Development, vol. 2, 2013, no. 1, pp. 34-37.

SHARIFI, A. 2020. Urban sustainability assessment: An overview and bibliometric analysis. In Ecological Indicators, vol. 121, 2020, pp. 107102. https://doi.org/10.1016/j. ecolind.2020.107102

SILVA, S. T. - TEIXEIRA, A. A. C. 2009. On the divergence of evolutionary research paths in the past 50 years: A comprehensive bibliometric account. In Journal of Evolutionary Economics, vol. 19, 2009, no. 5. https://doi.org/10.1007/s00191-008-0121-9

SILVESTRE, B.S. 2015. Sustainable supply chain management in emerging economies: Environmental turbulence, institutional voids and sustainability trajectories. In International Journal of Production Economics, vol. 167, 2015, pp. 156-169. https://doi.org/10.1016/.i.ipe.2015.05.025

SOOSARAEI, M. - KHASSEH, A. A. - FAKHAR, M. - HEZARJARIBI, H. Z. 2018. A decade bibliometric analysis of global research on leishmaniasis in Web of Science database. In Annals of Medicine and Surgery, vol. 26, 2018, pp. 30-37. https://doi. org/10.1016/j.amsu.2017.12.014

SWEILEH, W. M. - AL-JABI, S. W. - SAWALHA, A. F. - ZYOUD, S. H. 2014. Bibliometric analysis of nutrition and dietetics research activity in Arab countries using ISI Web of Science database. In SpringerPlus, vol. 3, 2014, no. 1, pp. 1-7. https://doi. org/10.1186/2193-1801-3-718

UDOMSAP, A. D. - HALLINGER, P. 2020. A bibliometric review of research on sustainable construction, 1994-2018. In Journal of Cleaner Production, vol. 254, 2020.

van de VRANDE, V. - de JONG, J. P. J. - VANHAVERBEKE, W. - de ROCHEMONT, M. 2009. Open innovation in SMEs: Trends, motives and management challenges. In Technovation, vol. 29, 2009, no. 6-7, pp. 423-437. https://doi.org/10.1016/j. technovation.2008.10.001 van ECK, N. J. - WALTMAN, L. 2010. Software survey: VOSviewer, a computer program. In Scientometrics, 2010, pp. 523-538.

VELOUTSOU, C. - MAFE, C. R. 2020. Brands as relationship builders in the virtual world: A bibliometric analysis. In Electronic Commerce Research and Applications, vol. 39, 2020.

WALLSTEN, S. J. 2000. The Effects of Government-Industry R \& D Programs on Private $R$ \& D: The Case of the Small Business Innovation Research Program. In The RAND Journal of Economics, vol. 31, 2000, no. 1, pp. 82-100.

XIE, H. - ZHANG, Y. - DUAN, K. 2020. Evolutionary overview of urban expansion based on bibliometric analysis in web of science from 1990 to 2019. In Habitat International, vol. 95, 2020, pp. 102100. https://doi.org/10.1016/j.habitatint.2019.102100

XU, G.-Q. et al. 2019. Identification and profiling of microRNAs expressed in oral buccal mucosa squamous cell carcinoma of Chinese hamster. In Scientific Reports, 2019.

YE, N. et al. 2020. A bibliometric analysis of corporate social responsibility in sustainable development. In Journal of cleaner producation, vol. 272, 2020.

YILDIZ, T. 2019. Examining The Concept of Industry 4.0 Studies Using Text Mining and Scientific Mapping Method. In Procedia Computer Science, vol. 158, 2019, pp. 498 507.

ZENG, S. X. - XIE, X. M. - TAM, C. M. 2010. Relationship between cooperation networks and innovation performance of SMEs. In Technovation, vol. 30, 2010, no. 3, pp. 181194. https://doi.org/10.1016/j.technovation.2009.08.003

ZOU, X. - YUE, W. L. - VU, H. L. 2018. Visualization and analysis of mapping knowledge domain of road safety studies. In Accident Analysis \& Prevention, vol. 118, 2018, pp. 131-145.

\section{Contact address}

Al-Hanakta Reham, Doctoral School of Economics and Regional Sciences, Hungarian University of Agriculture and Life Sciences, Gödöllö, Hungary; Páter K. str. 1, H-2100 Gödöllő, Hungary; mobile: +3670 65873 41; e-mail: Al-Hanakta.Reham.Yahia@hallgato.uni-szie.hu 